OPEN ACCESS

Edited by:

Aaron C. Petrey,

The University of Utah, United States

Reviewed by:

Toshiyuki Murai,

Osaka University, Japan

Eva Turley,

University of Western Ontario, Canada

*Correspondence:

Pauline Johnson pauline@mail.ubc.ca

Specialty section:

This article was submitted to Inflammation,

a section of the journal

Frontiers in Immunology

Received: 01 October 2019 Accepted: 08 January 2020 Published: 30 January 2020

Citation:

Dong Y, Arif AA, Guo J, Ha Z,

Lee-Sayer SSM, Poon GFT, Dosanjh M, Roskelley CD, Huan $T$ and Johnson P (2020) CD44 Loss Disrupts

Lung Lipid Surfactant Homeostasis

and Exacerbates Oxidized

Lipid-Induced Lung Inflammation.

Front. Immunol. 11:29.

doi: $10.3389 /$ fimmu.2020.00029

\section{CD44 Loss Disrupts Lung Lipid Surfactant Homeostasis and Exacerbates Oxidized Lipid-Induced Lung Inflammation}

\author{
Yifei Dong ${ }^{1}$, Arif A. Arif ${ }^{1,2}$, Jian Guo ${ }^{3}$, Zongyi Ha ${ }^{1}$, Sally S. M. Lee-Sayer ${ }^{1}$, \\ Grace F. T. Poon ${ }^{1}$, Manisha Dosanjh ${ }^{1}$, Calvin D. Roskelley ${ }^{2}$, Tao Huan ${ }^{3}$ and \\ Pauline Johnson ${ }^{1 *}$ \\ ${ }^{1}$ Department of Microbiology and Immunology, University of British Columbia, Vancouver, BC, Canada, ${ }^{2}$ Department of \\ Cellular and Physiological Sciences, University of British Columbia, Vancouver, BC, Canada, ${ }^{3}$ Department of Chemistry, \\ University of British Columbia, Vancouver, BC, Canada
}

Alveolar macrophages (AMs) are CD44 expressing cells that reside in the alveolar space where they maintain lung homeostasis by serving critical roles in immunosurveillance and lipid surfactant catabolism. AMs lacking CD44 are unable to bind the glycosaminoglycan, hyaluronan, which compromises their survival and leads to reduced numbers of AMs in the lung. Using RNA sequencing, lipidomics and multiparameter flow cytometry, we demonstrate that $\mathrm{CD} 44^{-/-}$mice have impaired AM lipid homeostasis and increased surfactant lipids in the lung. CD44-/- AMs had increased expression of CD36, a lipid scavenger receptor, as well as increased intracellular lipid droplets, giving them a foamy appearance. RNA sequencing revealed the differential expression of genes associated with lipid efflux and metabolism in CD44-/- AMs. Lipidomic analysis showed increased lipids in both the supernatant and cell pellet extracted from the bronchoalveolar lavage of $\mathrm{CD} 44^{-1-}$ mice. Phosphatidylcholine species, cholesterol, oxidized phospholipids and levels of reactive oxygen species (ROS) were increased in $\mathrm{CD} 44^{-/-}$AMs. Oxidized phospholipids were more cytotoxic to $\mathrm{CD} 44^{-/-} \mathrm{AMs}$ and induced greater lung inflammation in $\mathrm{CD} 44^{-/-}$mice. Reconstitution of $\mathrm{CD} 44^{+/+}$mice with $\mathrm{CD} 44^{-/-}$bone marrow as well as adoptive transfer of $\mathrm{CD} 44^{-/-}$AMs into $\mathrm{CD} 44^{+/+}$mice showed that lipid accumulation in CD44-/- AMs occurred irrespective of the lung environment, suggesting a cell intrinsic defect. Administration of colony stimulating factor 2 (CSF-2), a critical factor in $\mathrm{AM}$ development and maintenance, increased AM numbers in CD44-/- mice and decreased phosphatidylcholine levels in the bronchoalveolar lavage, but was unable to decrease intracellular lipid accumulation in CD44-/- AMs. Peroxisome proliferator-activated receptor gamma (PPAR $\gamma$ ), downstream of CSF-2 signaling and a regulator of lipid metabolism, was reduced in the nucleus of $\mathrm{CD} 44^{-/-} \mathrm{AMs}$, and PPAR $\gamma$ inhibition in normal AMs increased their lipid droplets. Thus, CD44 deficiency causes defects in AMs that lead to abnormal lipid accumulation and oxidation, which exacerbates oxidized lipid-induced lung inflammation. Collectively, these findings implicate CD44 as a regulator of lung homeostasis and inflammation.

Keywords: CD44, alveolar macrophage, lung surfactant lipids, oxidized lipids, lipidomics, flow cytometry, RNA sequencing, lung inflammation 


\section{INTRODUCTION}

Alveolar macrophages (AMs) are important for lung homeostasis, playing key roles in immunosurveillance and lipid surfactant catabolism (1). They are fetal monocyte-derived tissue resident macrophages (2) in the alveolar space that require colony stimulating factor 2 (CSF-2 also known as GM-CSF) $(2,3)$, peroxisome proliferator-activated receptor gamma $(\operatorname{PPAR} \gamma)(4)$, and transforming growth factor beta (TGF $\beta)(5)$ for their development, maturation and survival. The deficiency of any of these factors leads to the accumulation of immature macrophages which are unable to catabolize surfactant lipids, and this leads to the buildup of lipids in the immature AMs which take on a foamy appearance. Consequently, lung surfactant lipids build up in the alveolar space and this can lead to pulmonary alveolar proteinosis (PAP) $(6,7)$. While primary PAP is attributed to defective CSF-2 signaling, the causes of secondary PAP are largely unknown (7). CSF-2 induces the expression of PPAR $\gamma$ in fetal lung monocytes, which is critical for the generation of the AM gene signature (4). PPAR $\gamma$ is also important for lipid catabolism (8-10) in mature AMs (4). TGF $\beta$ upregulates PPAR $\gamma$ expression and conditional deletion of the TGF $\beta$ receptor in macrophages leads to the accumulation of immature, lipid-laden foamy macrophages, showing a key role for TGF $\beta$ signaling in AM development (5). Autocrine TGF $\beta$, produced by mature AMs, also contributes to their self-maintenance and survival (5).

AMs have an important role in the clearance of pulmonary surfactant produced by alveolar epithelial cells which is typically made up of $80 \%$ polar lipids [primarily phosphatidylcholine (PC)], 10\% neutral lipids including cholesterol, and 10\% proteins $(1,7,11)$. AM numbers are reduced during lung damage and inflammation (12-14) and this leads to the accumulation of surfactant lipids in the alveolar space where they become susceptible to oxidation in the oxygen-rich environment of the lung, especially during inflammation when reactive oxygen species (ROS) are generated by inflammatory cells (15). Oxidized lipids are cytotoxic, and if they build up in AMs, lung function is compromised (16). For example, bleomycin-induced lung injury leads to inflammation, ROS production, phospholipid oxidation and the generation of foamy macrophages, which all contribute to lung dysfunction (16). In contrast, mice lacking a NADPHoxidase subunit that cannot generate ROS were protected from bleomycin-induced pulmonary damage and fibrosis (17). In humans, oxidized lipid cytotoxicity can lead to the lifethreatening acute respiratory distress syndrome (18) and lung phospholipid peroxidation is associated with asthma and chronic obstructive pulmonary disease progression (19). Furthermore, oxidized phosphatidylcholine (OxPC) is found in AMs from patients diagnosed with idiopathic interstitial pneumonia (20). Thus, oxidized lipids are an important component of the pathophysiology of lung disease, and the removal of excess surfactant lipids and oxidized lipids from the alveolar space by AMs is essential to maintain vital lung function and homeostasis.

Unlike most other macrophages at steady state, mature murine AMs express high levels of CD11c, Siglec F, and constitutively bind hyaluronan (HA) via its receptor, CD44 $(21,22)$. HA, a component of the extracellular matrix, is implicated in both lung homeostasis and inflammation (23). At homeostasis, CD44-dependent HA binding by AMs results in the formation of a pericellular HA coat that promotes their survival (12). AMs from $\mathrm{CD} 44^{-/-}$mice lack the HA coat, leading to a decrease in their viability and $\mathrm{CD} 44^{-/-}$mice have approximately half the normal number of AMs (12). In humans, CD44 expression is lower on AMs isolated from patients with diffuse panbronchiolitis (24) and chronic obstructive pulmonary disease (COPD) (25), and in mice, the depletion of AMs exaggerates pulmonary inflammatory responses $(26,27)$. Furthermore, $\mathrm{CD} 44^{-1-}$ mice treated with bleomycin are unable to resolve lung inflammation, resulting in a buildup of HA and apoptotic neutrophils $(28,29)$. Here, we investigated the impact of CD44 in lung homeostasis and inflammation by studying AMs from $\mathrm{CD} 44^{-/-}$mice.

\section{MATERIALS AND METHODS}

\section{Mice}

C57BL/6J $\quad\left(\mathrm{CD} 45.2^{+}\right), \quad$ B6.SJL-Ptprc ${ }^{\mathrm{a} P e p c}$ b/Boyj $\quad\left(\mathrm{CD} 45.1^{+}\right)$, C57BL/6J x BoyJ heterozygotes (CD45.1 $\left.{ }^{+}, \mathrm{CD} 45.2^{+}\right)$, and $\mathrm{CD} 44^{-/-}$mice were housed and bred in specific pathogen free facilities, as previously described (12). Experiments used 6-14 week-old, age and sex matched mice and were conducted with protocols approved by the University Animal Care Committee in accordance with the Canadian Council of Animal Care guidelines for ethical animal research.

\section{Reagents}

Fluorescein-conjugated HA (FL-HA), used to measure the ability of cells to bind HA, was prepared from rooster comb HA sodium salt of expected molecular mass 1-4 million and $<2 \%$ protein contamination, catalog no 5388 (Sigma-Aldrich), as previously described (12). Streptomyces hyaluronlyticus hyaluronidase (HA'se) and biotinylated HA-binding protein (HABP) were from Millipore, and streptavidin was from Thermo Fisher Scientific or eBioscience. Recombinant mouse CSF-2 (carrier free) was from BioLegend. L- $\alpha$-phosphatidylcholine (PC) was from Sigma-Aldrich. 1-palmitoyl-2-(5'-oxo-valeroyl)sn-glycero-3-phosphocholine (POVPC) was from Avanti Polar Lipids. Fatty acid free (FAF) BSA was from Roche Diagnostics. BODIPY 493/503, N-(7-Nitrobenz-2-Oxa-1,3-Diazol-4-yl)-1,2Dihexadecanoyl-sn-Glycero-3-Phosphoethanolamine (NBD$\mathrm{PE})$, and $2^{\prime}, 7^{\prime}$-dichlorodihydrofluorescein diacetate $\left(\mathrm{H}_{2} \mathrm{DCFDA}\right)$ were from Thermo Fisher Scientific. The PPAR $\gamma$ antagonist, T0070907, was from Tocris Bioscience. Fluorescent or biotinylated labeled CD11c (N418), CD11b (M1/70), Ly6C (HK1.4), CD14 (SA2-8), CD45.1 (A20), CD45.2 (104), CD200R (OX110), MHC II (M5/114.15.2), Siglec F (1RNM44N), and SIRP $\alpha$ (P84) were from Thermo Fisher Scientific; CD36 (HM36) and CD206 (C068C2) were from Biolegend; CD44 (IM7) was from Ablab; Ly6G (1A8), Siglec F (E50-2440), and mouse IgG1к isotype were from BD Biosciences; CD116 (698423) and MerTK (polyclonal BAF591) were from R\&D; PPAR $\gamma$ (81B8) was from Cell Signaling Technologies, and anti-OxPC (E06) was from Avanti Polar Lipids. 


\section{In vivo Experiments}

Bone marrow (BM) reconstitution into irradiated recipients was essentially as described in Dong et al. (12). POVPC $(200 \mu \mathrm{g})$ in $50 \mu \mathrm{l} \mathrm{PBS}$, or CSF-2 (2 $\mu \mathrm{g}$ daily) was given to mice by intratracheal instillation (i.t.) by laryngoscopic manipulation, and the bronchoalveolar lavage (BAL) analyzed 3 or 7 days later, respectively. For adoptive transfer experiments, 2-3 $\times$ $10^{5} \mathrm{CD} 44^{+/+}$or $\mathrm{CD} 44^{-/-}$AMs were transferred by i.t. into $\mathrm{CD} 45.1^{+} \mathrm{CD} 44^{+/+}$or CD $45.2^{+} \mathrm{CD} 44^{-/-}$mice, and BAL was analyzed on day 7 .

\section{Isolation of Bronchoalveolar Lavage (BAL) Cells for RNAseq, Flow Cytometry or in vitro Analysis}

BAL was isolated from $\mathrm{CD} 44^{+/+}$and $\mathrm{CD} 44^{-/-}$mice using 4 $\times 700 \mu \mathrm{l} \mathrm{PBS}, 2 \mathrm{mM}$ EDTA and the BAL cells (>95\% AMs from naïve mice) were treated by RBC lysis buffer $(0.84 \%$ $\mathrm{NH}_{4} \mathrm{Cl}$ in $10 \mathrm{mM}$ Tris $\mathrm{pH}$ 7.2) for $5 \mathrm{~min}$, centrifuged and either subjected to RNA extraction using RNeasy Mini Kit (Qiagen) or counted manually using the hemocytometer and trypan blue, and prepared for flow cytometry as previously described (12). Alternatively, AMs were washed once with PBS and incubated with $2.5 \mu \mathrm{M}$ BODIPY 493/503 in PBS, $5 \mu \mathrm{M} \mathrm{H}_{2}$ DCFDA in PBS, or $10 \mu \mathrm{M}$ NBD-PE in RPMI for $30 \mathrm{~min}$ at $37^{\circ} \mathrm{C}$ prior to flow cytometry. Or, AMs were incubated with $1 \% \mathrm{EtOH}$ (vehicle solvent), $50 \mu \mathrm{M}$ PC, or $50 \mu \mathrm{M}$ POVPC in PBS for $1 \mathrm{~h}$ at $37^{\circ} \mathrm{C}$, then analyzed with Annexin V-PE and DAPI by flow cytometry (12). HABP was used to detect cell surface HA by flow cytometry (12). For blocking FL-HA binding on AMs, ex vivo CD $44^{+/+}$and CD44 $4^{-/-}$AMs were incubated with the CD44 blocking antibody KM81 (1:100 from tissue culture supernatant) for $30 \mathrm{~min}$ at $4^{\circ} \mathrm{C}$. All flow cytometry was performed using the BD LSR II.

\section{In vitro AM Culture}

AMs were cultured with $20 \mathrm{ng} / \mathrm{ml}$ of recombinant CSF-2 in RPMI containing $1 \% \mathrm{BSA}$, in the presence or absence of $500 \mu \mathrm{M} \mathrm{PC}$ or $1 \mu \mathrm{M}$ T0070907 in a 96-well non-tissue culture treated plate for $48 \mathrm{~h}$, harvested using versene, and the cells analyzed by flow cytometry. For culture with PC, 1\% FAF BSA was used.

\section{Intracellular Labeling of AMs}

AMs were isolated by BAL with PBS $2 \mathrm{mM}$ EDTA and fixed with $2 \%$ paraformaldehyde immediately for $10 \mathrm{~min}$ at room temperature, washed twice with PBS, labeled with the E06 or PPAR $\gamma$ antibody intracellularly using the Intracellular Fixation \& Permeabilization Buffer Set (Thermo Fisher Scientific).

\section{Analysis of BAL Fluid}

BAL isolated using PBS $2 \mathrm{mM}$ EDTA was centrifuged and the supernatant and cell pellet collected. Hyaluronan Quantikine ELISA Kit (R\&D Systems) was used to determine the HA concentration in the BAL supernatant. Total protein was determined using the Pierce BCA Protein Assay Kit (Thermo Fisher Scientific). Total PC concentration was determined using the Phospholipase C assay kit (Wako Diagnostics).

\section{Gas Chromatography Analysis for Cholesterol}

Lipids were extracted twice from $1 \mathrm{ml}$ BAL supernatant by adding $6 \mathrm{ml}$ of $2: 1 \mathrm{v} / \mathrm{v}$ chloroform: methanol, with $1 \%$ acetic acid. Organic solvents were evaporated under a stream of nitrogen gas. Lipid extracts were resuspended in pyridine and then an equal part of N,O-bis(trimethylsilyl)trifluoro-acetamide with trimethylchlorosilane. Samples were spiked with $10 \mu \mathrm{M}$ cholestane as an internal standard and analyzed by gaschromatography mass spectrometry (GC-MS).

\section{Flow Cytometric Analysis}

Flow cytometry was analyzed using FlowJo VX (Treestar). Flow cytometry plots shown were first gated by size, singlets, and live/dead stain. AMs were then gated as $\mathrm{CD} 11 \mathrm{c}^{+}$and Siglec $\mathrm{F}^{+}$ (Supplementary Figures 1A,B). Fold difference was calculated by dividing each $\mathrm{CD} 44^{+/+}$and $\mathrm{CD} 44^{-/-}$biological replicate by the mean of $\mathrm{CD} 44^{+/+}$samples in each experiment.

\section{Confocal Microscopy}

AMs labeled with BODIPY or E06 and DAPI were mounted onto Superfrost ${ }^{+}$microscope slides (Thermo Fisher Scientific). Whole cell image stacks were acquired using a Leica Sp8 microscope. Maximum stack projections were analyzed using ImageJ 1.51 (NIH). BODIPY stained lipid droplets were identified using a trainable segmentation function in Image), followed by particle analysis, and droplet masks were applied onto the raw images to measure number, pixel intensity, and droplet size. E06 labeled droplets were also counted. PPAR $\gamma$ and DAPI labeled AMs were acquired using a Leica Sp5. Total nuclear PPAR $\gamma$ was measured within the $\mathrm{DAPI}^{+}$nuclear area and quantified as mean pixel intensity (MPI). Immunofluorescence of $12 \mu \mathrm{m}$ lung tissue cryosections was measured as previously described (12) and analyzed using ImageJ for HABP mean pixel intensity (MPI), where HA-rich bronchioles were excluded from the analysis.

\section{RNAseq Analysis}

RNA from three independent $\mathrm{CD} 44^{+/+}$and three $\mathrm{CD} 44^{-/-}$ samples were pooled from the BAL of 4,2 , or 2 female mice, respectively.

\section{Illumina RNA Sequencing}

RNA was sequenced by the UBC Biomedical Research Center. RNA quality, $18 S$ and $28 S$ ribosomal RNA with $\mathrm{RIN}=9.6$, was determined by Agilent 2100 Bioanalyzer following the standard protocol for NEBNext Ultra II Stranded mRNA (New England Biolabs). Sequencing was performed on the Illumina NextSeq 500 with paired end $42 \mathrm{bp} \times 42 \mathrm{bp}$ reads. De-multiplexed read sequences were then aligned to the Mus musculus (mm10) reference sequence using Spliced Transcripts Alignment to a Reference, STAR (https://www.ncbi.nlm.nih.gov/ pubmed/23104886), aligners. The sequence data is available at GEO database, accession number: GSE138445.

\section{Cufflinks and Cuffdiff}

Assembly and differential expression were estimated using Cufflinks (http://cole-trapnell-lab.github.io/cufflinks/) through 
Cufflinks Assembly \& DE version 2.1.0 which included Cuffdiff analysis (30). Gene differences with a q value ( $p$-value adjusted for false discovery rate) $<0.05$ were considered significant.

\section{Metascape Analysis}

Metascape analysis was performed on the genes annotated as significantly different from the Cuffdiff analysis (31). Gene IDs were entered and analyzed as $M$. musculus. Significantly different GO pathways were obtained as an output from Metascape.

\section{R Scripts and Heatmaps}

$\mathrm{R}$ language was used for bioinformatic analysis of RNA sequencing results using RStudio Version 1.1.442. Gene ID was converted to Entrez ID using Annotables: Ensembl 90 conversion chart (32). Heatmaps were created using $\mathrm{R}$ library, "pheatmap()." The input for heatmaps were a list of differentially expressed genes in specific GO pathways and their corresponding fragments per kilobase of transcript per million mapped reads (FPKMs). FPKM values were obtained from Illumina RNA-Sequencing.

\section{String Analysis}

All 200 significant genes $(q<0.05)$ were input into the String Consortium (33). String Consortium maps the interactions between genes based on text mining, experiments, databases, co-expression, neighborhood, gene fusion, and co-occurrence.

\section{Mass Spectrometry, Lipidomics, and Analysis}

BAL Cell Pellet and Supernatant Sample Preparation The BAL from $8 \mathrm{CD}_{4} 4^{+/+}$and $8 \mathrm{CD} 44^{-/-}$female mice were spun down to generate a supernatant and cell pellet for each sample. Lipids were extracted from the BAL pellets, CD $44^{+/+}$(WT1-8) and CD44-/- (KO1-8) with $400 \mu \mathrm{l}$ ice cold extraction solvent [methanol:acetonitrile $(\mathrm{ACN})$ : water $=$ 2:1:1, v:v:v] followed by three freeze-thaw cycles. Proteins were precipitated at $-20^{\circ} \mathrm{C}$ for $2 \mathrm{~h}$, then $900 \mu \mathrm{l}$ methyl tert-butyl ether (MTBE) was added and vortexed for $90 \mathrm{~min}$ on an open-air microplate shaker. One hundred and seventy microliter $\mathrm{H}_{2} \mathrm{O}$ was then added into the solution followed by centrifugation $(17,530 \mathrm{~g}$, $4^{\circ} \mathrm{C}, 1 \mathrm{~min}$ ) to accelerate the phase separation. CD $44^{+/+}$(WT18 ) and $\mathrm{CD}_{4} 4^{-/-}$(KO1-8) BAL supernatant samples (3 ml each) were thawed on ice and $3 \mathrm{ml}$ MTBE added and vortexed for $90 \mathrm{~min}$ on an open-air microplate shaker. In both cases, the upper organic phase was carefully transported to a $1.5 \mathrm{ml}$ Eppendorf vial and concentrated by Speed-vac at $4^{\circ} \mathrm{C}$. The concentrated pellets were subsequently reconstituted with ACN:isopropyl alcohol(IPA) = 1:1, v:v for LC-MS analysis. One method control (MC) was prepared using the same procedure but with no sample in the vial. One quality control (QC) was prepared by pooling $10 \mu \mathrm{l}$ from each of the 16 reconstituted solutions (8 WT+8 $\mathrm{KO})$. QC was injected between every four sample injections to ensure the instrument was stable and the sample injection volume was optimized.

\section{Liquid Chromatography Mass Spectrometry (LC-MS)} Analysis

The LC-MS analysis was performed on Bruker Impact $\mathrm{II}^{\mathrm{TM}}$ UHR-QqTOF (Ultra-High Resolution Qq-Time-Of-Flight) mass spectrometer coupled with a Agilent 1290 Infinity $^{\mathrm{TM}}$ II LC system. LC separation was performed on a Waters ACQUITY UPLC BEH C18 Column (130 ̊, $1.7 \mu \mathrm{m}, 1.0 \mathrm{~mm} \times 100 \mathrm{~mm})$. Two microliter sample solutions of each replicate, MC and QC were injected in a random order. Two microliter Sodium formate was injected within each run for internal calibration. The mobile phase A was $60 \% \mathrm{ACN} 40 \% \mathrm{H}_{2} \mathrm{O}[2 \mathrm{mM}$ ammonium acetate $\left(\mathrm{NH}_{4} \mathrm{Ac}\right)$ in positive mode, $5 \mathrm{mM} \mathrm{NH}_{4} \mathrm{Ac}$ in negative mode]; mobile phase B was $90 \%$ IPA $10 \% \mathrm{ACN}\left(2 \mathrm{mM} \mathrm{NH}_{4} \mathrm{Ac}\right.$ in positive mode, $5 \mathrm{mM} \mathrm{NH}_{4} \mathrm{Ac}$ in negative mode). The chromatographic gradient was run at a flow rate of $0.100 \mathrm{ml} / \mathrm{min}$ as follows: $0-8$ min: linear gradient from 95 to $60 \% \mathrm{~A} ; 8-14$ min: linear gradient from 60 to $30 \% \mathrm{~A} ; 14-20 \mathrm{~min}$ : linear gradient from 30 to $5 \% \mathrm{~A}$; 20-23 min: hold at 5\% A; 23-24 min: linear gradient from 5 to 95\% A; 24-33 min: hold at 95\% A. The mass spectrometer was operated in Auto MS/MS mode. The ionization source capillary voltage was set to $4.5 \mathrm{kV}$ in positive scanning mode and -3.5 $\mathrm{kV}$ in negative scanning mode. The nebulizer gas pressure was set to 1.0 bar. The dry gas temperature was set to $220^{\circ} \mathrm{C}$. The collision energy for MS/MS was set to $7 \mathrm{eV}$. The data acquisition was performed in a range of $50-1,200 \mathrm{~m} / \mathrm{z}$ at a frequency of $8 \mathrm{~Hz}$.

\section{Data Interpretation}

Bruker Data Analysis software was used to calibrate the spectra using sodium formate as the internal reference. Then the raw data files with format of ".d" were converted to format of ".abf" using AbfConverter. The converted files were then uploaded onto MS-DIAL for lipid feature extraction and alignment. Lipids identification was carried out using LipidBlast available in MS$\operatorname{DIAL}(34,35)$. The parameters were set as follows: MS1 tolerance was $0.01 \mathrm{Da}$; MS2 tolerance was $0.05 \mathrm{Da}$; retention time tolerance was $0.5 \mathrm{~min}$. The alignment result was exported in a "csv." file. Fold change (FC, calculated as CD $44^{-/-} / \mathrm{CD} 44^{+/+}$) and $p$-values between $\mathrm{CD} 44^{+/+}$and $\mathrm{CD} 44^{-/-}$groups were calculated using a two tails distribution, homoscedastic $t$ test in Microsoft Excel. The lipids with $\mathrm{FC}>1.5$ or $\mathrm{FC}<0.67$, and $p<0.05$ were selected as being significantly different between the CD $44^{+/+}$ and $\mathrm{CD} 44^{-/-}$groups.

\section{Statistics}

Statistical analysis used is described in the figure legends. The majority of graphs were generated using GraphPad Prism 6 and the data shown are the average \pm standard deviation. Significance was defined as ${ }^{*} p<0.05,{ }^{* *} p<0.01,{ }^{* * *} p<0.001$. Non-paired Student's $t$-tests were used to compare biological replicates from individual $\mathrm{CD} 44^{+/+}$and $\mathrm{CD} 44^{-/-}$mice. Paired Student's $t$-tests were used in adoptive transfer experiments, where $\mathrm{CD} 44^{+/+}$and $\mathrm{CD} 44^{-/-}$cells are within the same mouse, in each biological replicate. Welch's $t$-test, which does not assume equal variance, was used to compare HA deposition in the lung, to account for the variability that can arise in inflammation between each animal, and between $\mathrm{CD} 44^{+/+}$and $\mathrm{CD} 44^{-/-}$ 


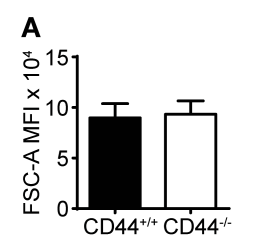

C

B

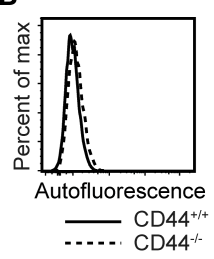

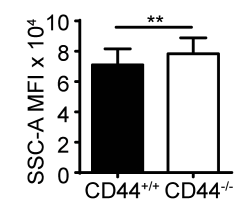
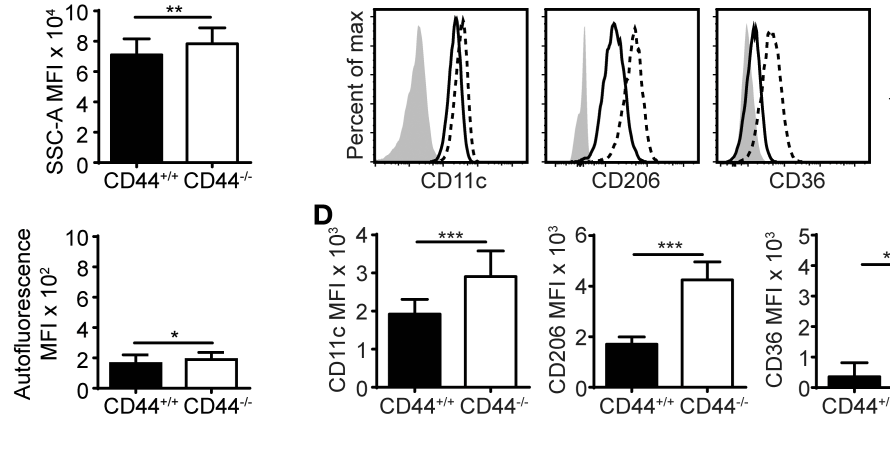

D

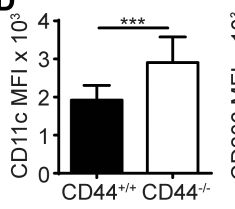

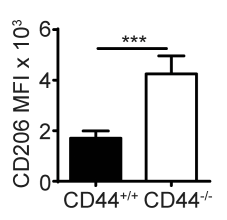

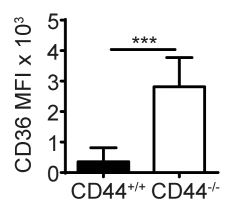

FIGURE 1 | CD44-/- mice have abnormal AMs. (A,B) Bar graphs and representative flow cytometry histograms comparing the FSC-A (cell size), SSC-A (cell granularity), and autofluorescence of $\mathrm{CD} 44^{+/+}$and $\mathrm{CD} 44^{-/-}$AMs from BAL of naïve mice. (C,D) Representative flow cytometry histograms and graphs comparing the $\mathrm{MFI}$ of cell surface phenotype of $\mathrm{CD} 44^{+/+}$and $\mathrm{CD} 44^{-/-} \mathrm{AMs}$, where the background MFI of autofluorescence from unlabeled $\mathrm{CD} 44^{+/+}$or $\mathrm{CD} 44^{-/-}$cells was subtracted from the values shown. Data show an average of two experiments \pm SD, each with three to five CD44 ${ }^{+/+}$and $C D 44^{-/-}$mice, except for in (A) which was the average of BAL AMs from $44 \mathrm{CD} 44^{+/+}$and $\mathrm{CD} 44^{-/-}$mice over 12 experiments. Significance indicated as ${ }^{*} p<0.05,{ }^{* *} p<0.01,{ }^{* * *} p<0.001$, non-paired Student's t-test.

groups. The homoscedastic $t$-test, which assumes equal variance, was performed on the lipidomics data.

\section{RESULTS}

\section{CD44-/- AMs Have Increased Cellular Granularity and Cell Surface Receptor Expression}

$\mathrm{CD} 44^{-/-}$mice have approximately $50 \%$ less AMs compared to normal $\mathrm{C} 57 \mathrm{Bl} / 6 \mathrm{~J}$ mice, as previously reported (12). These CD44-/- AMs express the characteristic AM markers: CD11c and Siglec F, but are unable to bind hyaluronan, an extracellular matrix glycosaminoglycan that promotes their survival (12). Here, flow cytometric analysis showed that $\mathrm{CD} 44^{-/-} \mathrm{AMs}$, gated as in Supplementary Figure 1A, were unable to bind fluorescein labeled HA (FL-HA), had a greater granularity (SSC) and a slightly higher autofluorescence than $\mathrm{CD} 44^{+/+}$ AMs (Figures 1A,B and Supplementary Figures 1B,E). In addition, there was a slight increase in the mean fluorescence intensity (MFI) of several cell surface molecules normally expressed on resident AMs (CD11c, CD206, CD200R, Sirp $\alpha$, MerTK) but Siglec F levels remained unchanged (Figures 1C,D and Supplementary Figures 1C,D). Adjusting for increased autofluorescence did not account for these changes. There was also increased expression of molecules not normally expressed on mature AMs (CD36, MHCII, CD11b, and PD-1) (Figures 1C,D and Supplementary Figures 1C,D). CD36 is a scavenger receptor for fatty acids and oxidized lipids $(36,37)$, raising the possibility that the increased SSC and autofluorescence may represent increased lipid content. To determine if cell surface HA bound on normal AMs physically affected the binding of antibodies and thus contributed to the phenotypic differences observed by flow cytometry, CD $44^{+/+}$and $\mathrm{CD} 44^{-/-}$AMs were treated with hyaluronidase (HA'se). This decreased the binding of $\mathrm{HABP}$ on $\mathrm{CD} 44^{+/+} \mathrm{AMs}$, indicating the removal of HA. HABP binding was reduced to the levels observed on $\mathrm{CD} 44^{-/-}$AMs, but not quite to the level of unstained cells, suggesting either some non-specific binding of HABP or incomplete removal of HA by HA'se. The HA'se treatment on CD44 ${ }^{+/+}$AMs did not change the MFI of cell surface receptors (Supplementary Figures 1F,G). These differences suggest CD44 deficiency causes changes in AMs.

\section{CD44+/+ and CD44-/- AMs Have Different Transcriptional Profiles at Steady-State}

To understand how the loss of CD44 could be impacting AMs, we performed RNAseq analysis on $\mathrm{CD} 44^{+/+}$and CD44-/- AMs. Approximately 200 genes with a q value of 0.05 or less were differentially expressed (Figure $2 \mathrm{~A}$ and Supplementary Table 1). The RNAseq data showed several transcriptional changes in $\mathrm{CD} 44^{-/-}$AMs that could affect lipid homeostasis in the CD44-/- AMs, notably ApoE, ApoC1, $A B C A 1, D G A T 2, L i p N$, and PLA2 $\gamma 7$ transcripts. Gene ontology analysis was performed to determine the pathways most affected by the loss of CD44 and this identified the greatest changes in the "sterol metabolic process," followed by differences in "the response to external stimulus," "protein phosphorylation pathways," "regulation of homeostatic process," and "regulation of sterol metabolic process" (Figures 2B,C). String analysis of the differentially expressed genes led to the identification of a gene cluster associated with sterol/cholesterol synthesis, and a broader cluster of genes involved in cell signaling, adhesion and migration (Supplementary Figure 2). Dissection of the sterol pathways led to a significant number of up and down-regulated genes associated with sterol/cholesterol synthesis and trafficking. Upregulated genes included those involved in lipid/cholesterol transport (ApoE, ApoC1, ABCA1), triacylglycerol synthesis (DGAT2), lipid catabolism ( $\operatorname{LipN})$, signaling (Src, Igf1, Igf2r), and immune function/antigen presentation (CD74, MHCII). Down regulated genes included phospholipase $(P L) A 2 \gamma 7, P L C \beta 1$, Plin1, Srebf2, $L D L R$, all involved in lipid homeostasis or its regulation. The transcription factor, Srebf2, is one of the 


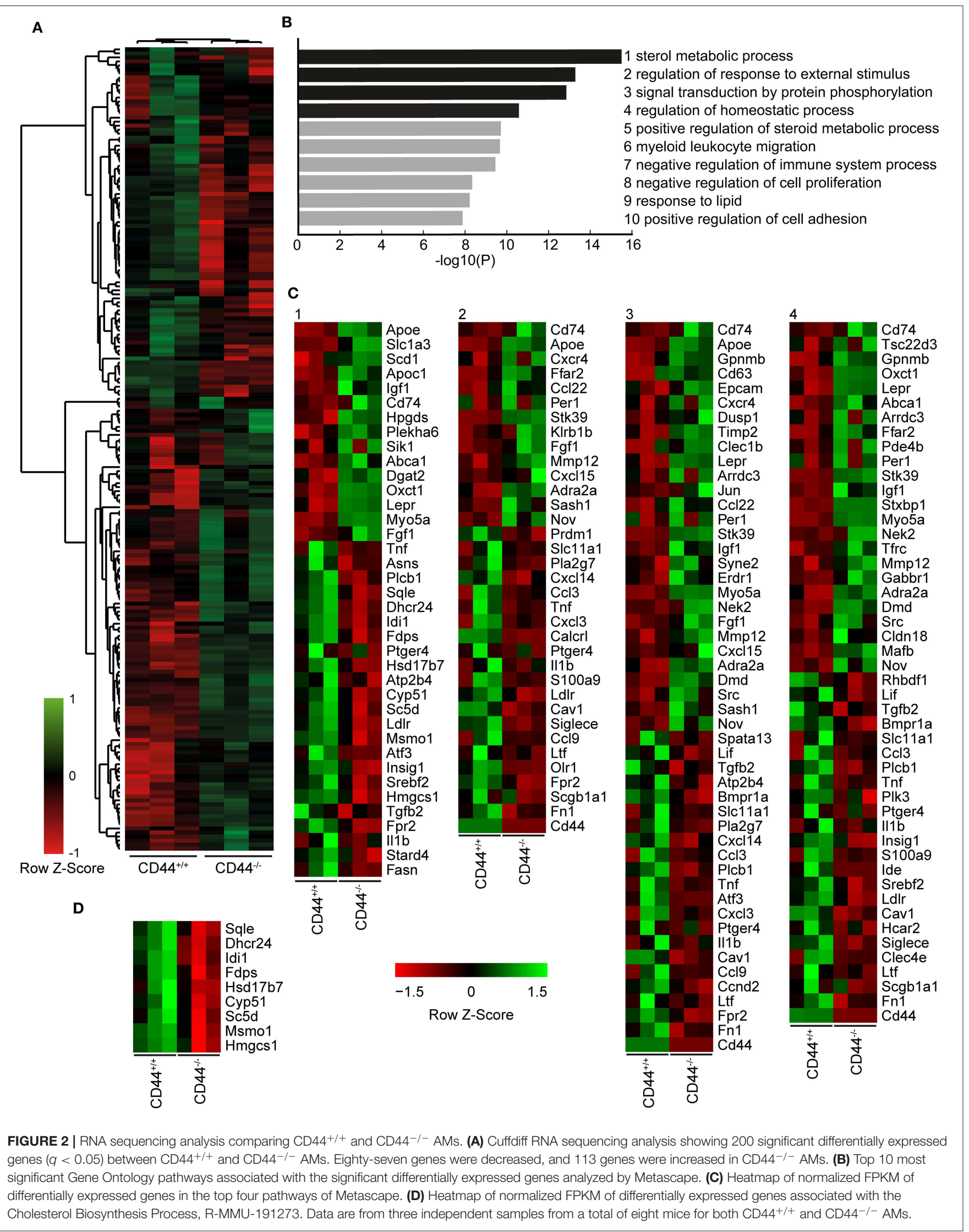


master regulators of cholesterol homeostasis (38). In keeping with this, several genes in sterol/cholesterol synthesis were also downregulated (Figure 2D). The down regulation of genes involved in cholesterol synthesis and LDL uptake, and the upregulation of genes involved in sequestering lipids/cholesterol $(A p o E)$ (39) and trafficking them out of the cell (ABCA1) (40), raised the possibility that the $\mathrm{CD} 44^{-/-} \mathrm{AMs}$ were responding to increased lipids/cholesterol.

\section{Lipidomic Analysis Reveals Altered Lipid Levels in the BAL Supernatant and Cell Pellet of CD44 ${ }^{-/-}$Mice}

To investigate if the transcriptional changes in $\mathrm{CD} 44^{-/-} \mathrm{AMs}$ affected lung lipid surfactant homeostasis in CD $44^{-/-}$mice, we employed a lipidomic approach. Lipids were extracted from the BAL supernatant and cell pellet of CD $44^{+/+}$and CD $44^{-/-}$mice and subjected to LC-MS analysis. From principal component analysis, the lipids from the cell pellet showed a clear difference between the $\mathrm{CD} 44^{+/+}$and $\mathrm{CD} 44^{-/-}$samples, whereas the difference between the lipids from the BAL supernatant was less clear (Figures 3A,B). The volcano plots showed a general trend of more lipids present in the $\mathrm{CD} 44^{-/}$samples, with greater differences observed in the cell pellet (Figures 3C,D). There were 429 lipid moieties identified from the BAL supernatant, and out of these, 52 were significantly changed $(p<0.05)$ by 1.5 -fold or more in the CD $44^{-/-}$samples. The majority of these, $49 / 52$, were increased in the CD44-/- AMs, typically by $1.5-2$-fold (Supplementary Table 2). The five most significantly changed lipids were three moieties of PC and lysophosphatidylglycerol (LPG) which were upregulated, while phosphatidyl serine (PS) was downregulated 4-fold. In the BAL cell pellet, 658 lipids moieties were detected, and out of these, 241 were significantly different: 186 lipids were more abundant and 55 were less abundant in the CD $44^{-/}$samples (Supplementary Table 3). In these samples the fold differences varied from 10-fold less to 18 times more. Six out of the top ten most significant changes were increases in PC moieties in the $\mathrm{CD} 44^{-/-}$cell pellet. Over 5-fold increases were observed with specific TAG, DAG, PA, PC, PG, and PE moieties. Notably, specific oxidized phospholipids (OxPLs) were increased up to 11-fold in the CD $44^{-/-}$cell pellet, and cholesterol was 2.6 -fold higher. Overall, there were many lipid moieties that were present at higher levels in the $\mathrm{CD} 44^{-/-}$BAL supernatant and cell pellet. When the lipids were grouped into their main classes and compared, the overall differences in the BAL supernatant were small, with a 1.1-1.5-fold increase in the CD44 ${ }^{-/}$samples, yet significant changes occurred for PC and lysophospholipids. Larger increases (1.7-2.6-fold) were observed in the CD44-/- cell pellet for cholesterol and the most prevalent lipids: PC, PE, PG and fatty acids, with 3.6-fold greater levels observed for OxPLs (Figure 3E).

\section{CD44-/- AMs Have More Lipid Droplets, Increased ROS and Higher OxPC Levels}

To corroborate the findings from the lipidomic experiments, PC and cholesterol levels were measured by ELISA and gas chromatography, respectively, and both were significantly increased in the BAL supernatant from $\mathrm{CD}_{4} 4^{-/-}$mice (Figures 4A,B). In addition, BODIPY 493/503, a dye that labels neutral lipids/lipid droplets was used to measure lipid levels in AMs. By confocal microscopy, we observed an increase in the number and size of lipid droplets in CD44-/AMs, and by flow cytometry we observed a significant increase in MFI of BODIPY, indicating a higher neutral lipid content (Figures 4C,D). These data further support a buildup of lipids in the BAL supernatant and AMs from CD44-/- mice.

To further investigate the increased presence of oxidized phospholipids in CD44-/- AMs, we used the E06 antibody that recognizes oxidized phosphatidylcholine (OxPC) (41). By confocal microscopy there was an increased number of OxPC droplets per cell and flow cytometry revealed a greater MFI in the CD44-/- AMs (Figures 4E,F). Labeling the AMs with a cell permeant fluorogenic dye that measures cellular ROS activity $\left(\mathrm{H}_{2} \mathrm{DCFDA}\right)$, showed a small but significant increase in ROS activity in the CD44-/- AMs compared to the CD44 ${ }^{+/+}$ AMs (Figure 4G). An increased accumulation of lipids and oxidized lipids in the cell are signs of a foamy macrophage and phospholipidosis (42), and this was further supported by the increased labeling of NBD-PE by CD44-/- AMs (Figure $4 \mathrm{H}$ ). To determine if the increased lipid and OxPC accumulation in $\mathrm{CD} 44^{-/-}$AMs resulted in increased oxidized lipid-induced toxicity, CD44 ${ }^{+/+}$and CD44-/- AMs were incubated with the oxidized phospholipid, POVPC, in vitro and compared with PC or the vehicle control ( $1 \%$ ethanol). The loss in AM viability caused by POVPC relative to ethanol or PC treatment was significantly greater in $\mathrm{CD} 44^{-/-}$AMs compared to $\mathrm{CD} 44^{+/+}$ AMs (Figure 4I), indicating increased sensitivity to OxPCinduced cellular toxicity.

\section{The Inflammatory Response to OxPC Is Exacerbated in CD44-/- Mice}

During an inflammatory response, there is increased oxidation of lung surfactant lipids, which can be cytotoxic to AMs if they accumulate. This oxidized lipid-induced cytotoxicity causes lung damage and further drives the inflammatory response $(15,16)$. To determine if the increased sensitivity of CD44-/$\mathrm{AMs}$ to OxPC observed in vitro translated into a more severe inflammatory response in $\mathrm{CD} 44^{-/-}$mice, we used a mouse model of OxPC-driven lung inflammation. POVPC was delivered i.t. to $\mathrm{CD} 44^{+/+}$and $\mathrm{CD} 44^{-/-}$mice and their weight loss was monitored over time (Figure 5A). Analysis of the cells in the BAL 3 days after POVPC instillation, showed leukocyte infiltration including monocytes, neutrophils, eosinophils, and $\mathrm{CD}_{1} \mathrm{~b}^{-}$cells, indicative of an inflammatory response in both $\mathrm{CD} 44^{+/+}$and $\mathrm{CD} 44^{-/-}$mice (Figure 5B). Apart from the tissue resident AMs, there were significantly greater numbers of other leukocytes (neutrophils, monocytes, eosinophils) in the BAL from CD44 $4^{-/}$mice (Figure 5C). Protein and HA levels, both indicators of lung inflammation and damage $(23,28,29)$, were also increased after POVPC treatment and were higher in the $\mathrm{BAL}$ from $\mathrm{CD} 44^{-/-}$mice 
A

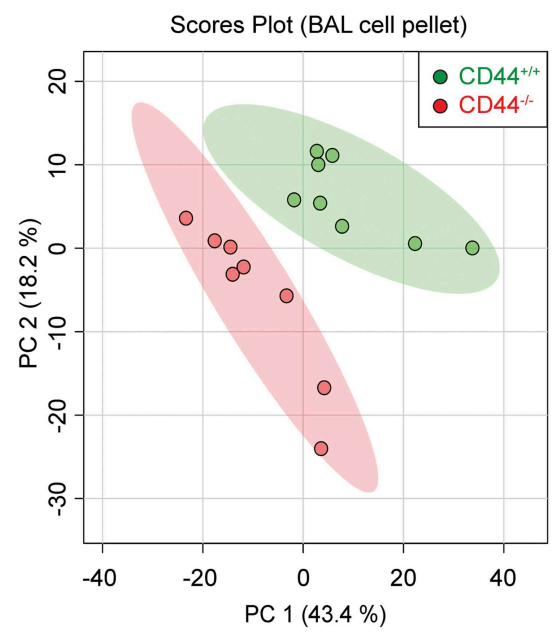

C

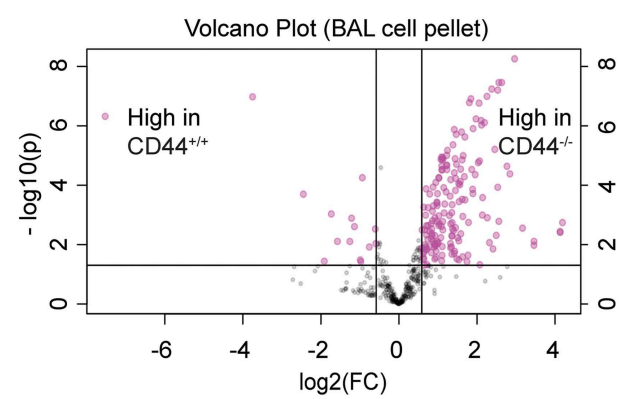

B

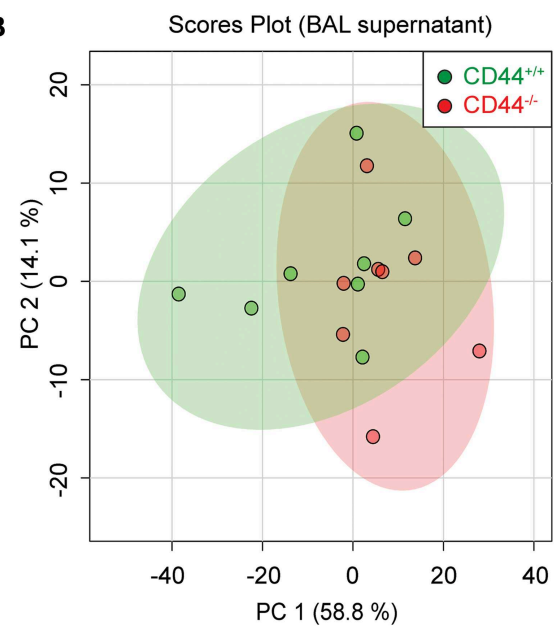

D

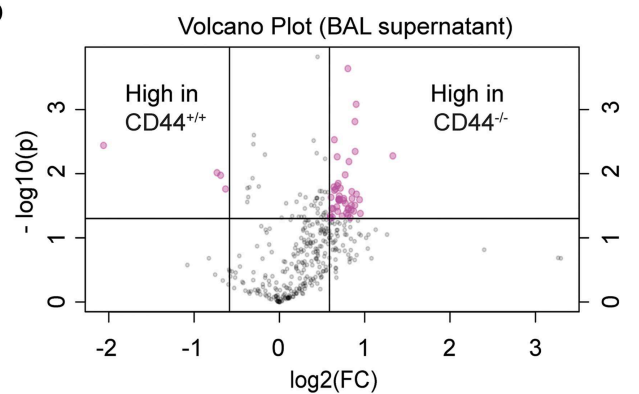

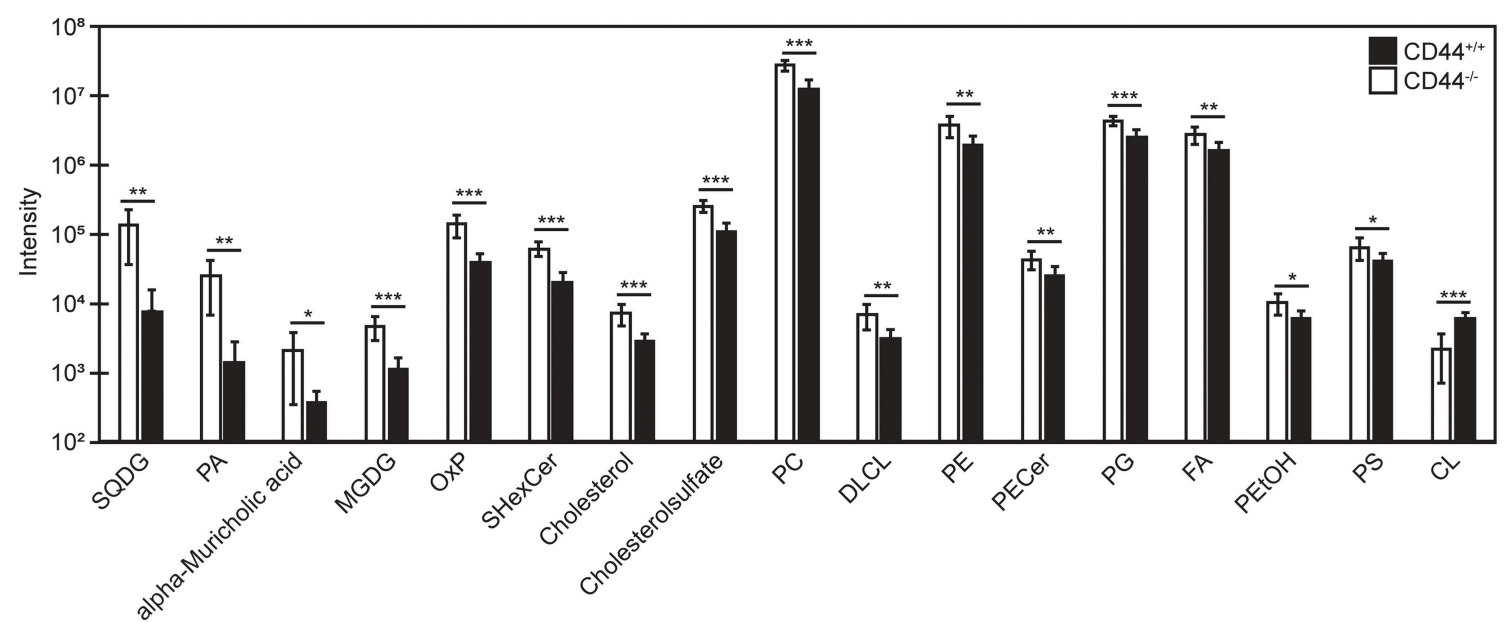

FIGURE 3 | Univariant and multivariant analysis of the differences in lipid composition between CD44+/+ and CD44-/- BAL samples. (A,B) Principal component analysis showing lipid differences from the BAL cell pellets and supernatants from CD44 $+/+$ and CD44-/- mice. (C,D) Volcano plots comparing the differences in lipid levels measured from the BAL cell pellets and supernatants from $\mathrm{CD} 44^{+/+}$and $\mathrm{CD} 44^{-/-}$mice. Pink dots represent lipid species with $>1.5$-fold difference between CD44 $4^{+/+}$and CD44 $4^{-/-}$samples, with $p<0.05$. (E) Graph showing lipids and lipid classes that are significantly different between CD44 ${ }^{+/+}$and CD44 ${ }^{-/-}$BAL cell pellets. Data show the average from $8 \mathrm{CD} 44^{+/+}$and $8 \mathrm{CD} 44^{-/-}$female mice. Significance indicated as ${ }^{*} p<0.05,{ }^{* \star} p<0.01,{ }^{* \star} p<0.001$, using a two tails distribution, homoscedastic $t$ test in Microsoft Excel.

(Figures 5D,E). There was also increased HA detected by HABP labeling in the lung tissue of $\mathrm{CD} 44^{-/}$mice 3 days after POVPC treatment, a sign of increased lung inflammation (Figures 5F,G). Thus, the increased sensitivity to OxPC toxicity in $\mathrm{CD} 44^{-/}$AMs leads to increased lung damage and greater lung inflammation.

\section{The Effect of the Alveolar Environment on CD44-/- AMs}

To further understand the cause of this lipid accumulation in the AMs and the BAL of $\mathrm{CD} 44^{-/-}$mice, we sought to distinguish between intrinsic and extrinsic AM factors. To address the contributions of the alveolar environment on the 


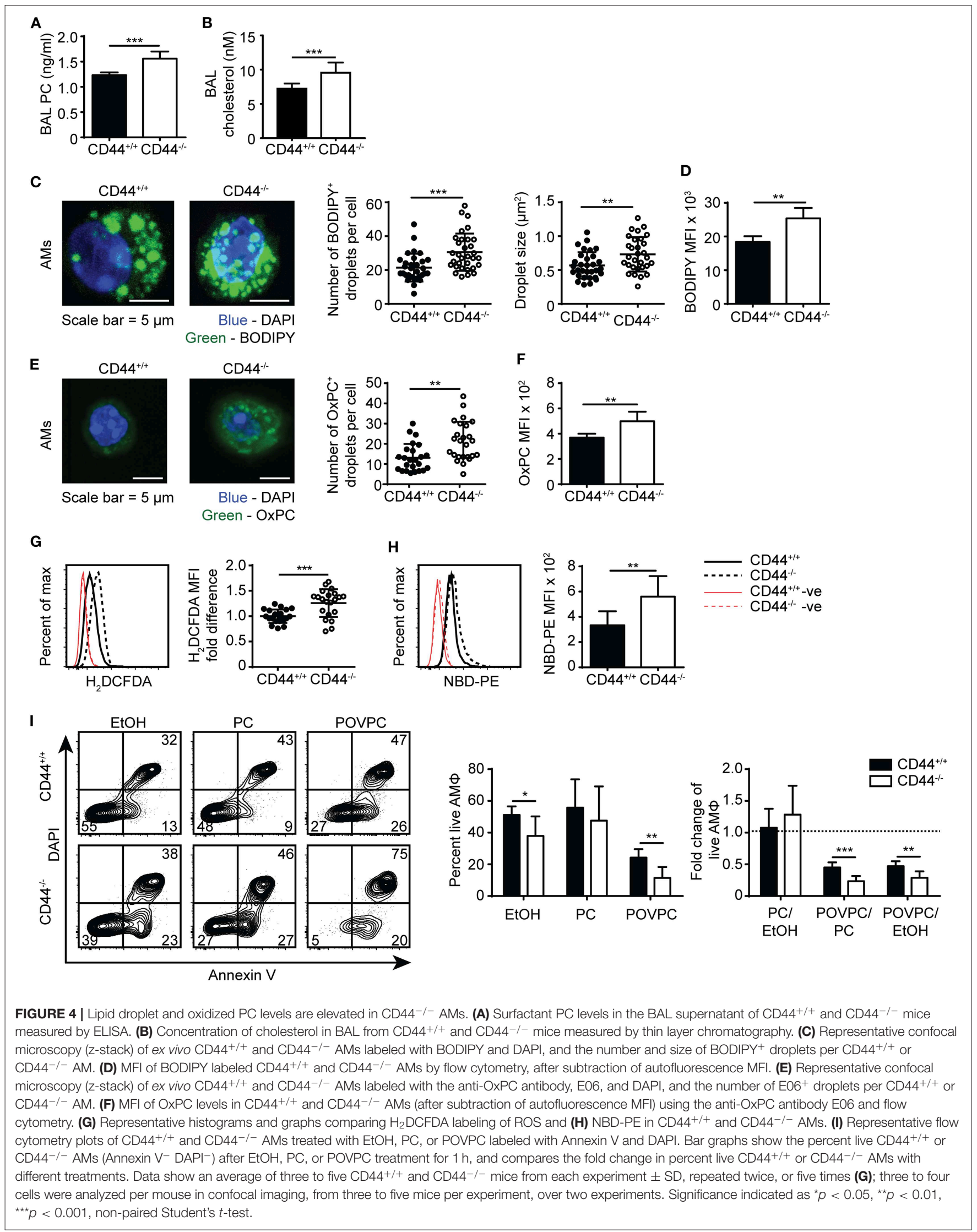




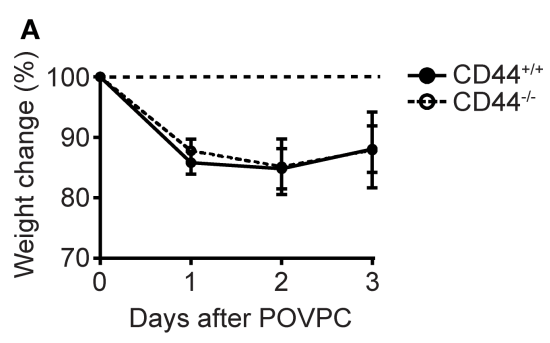

B

Day 3 OxPC

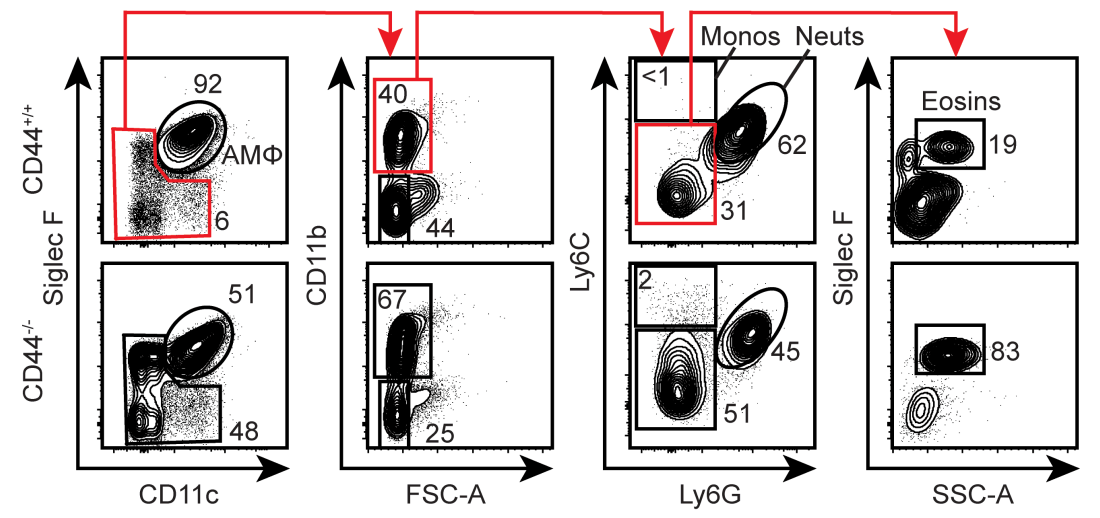

C
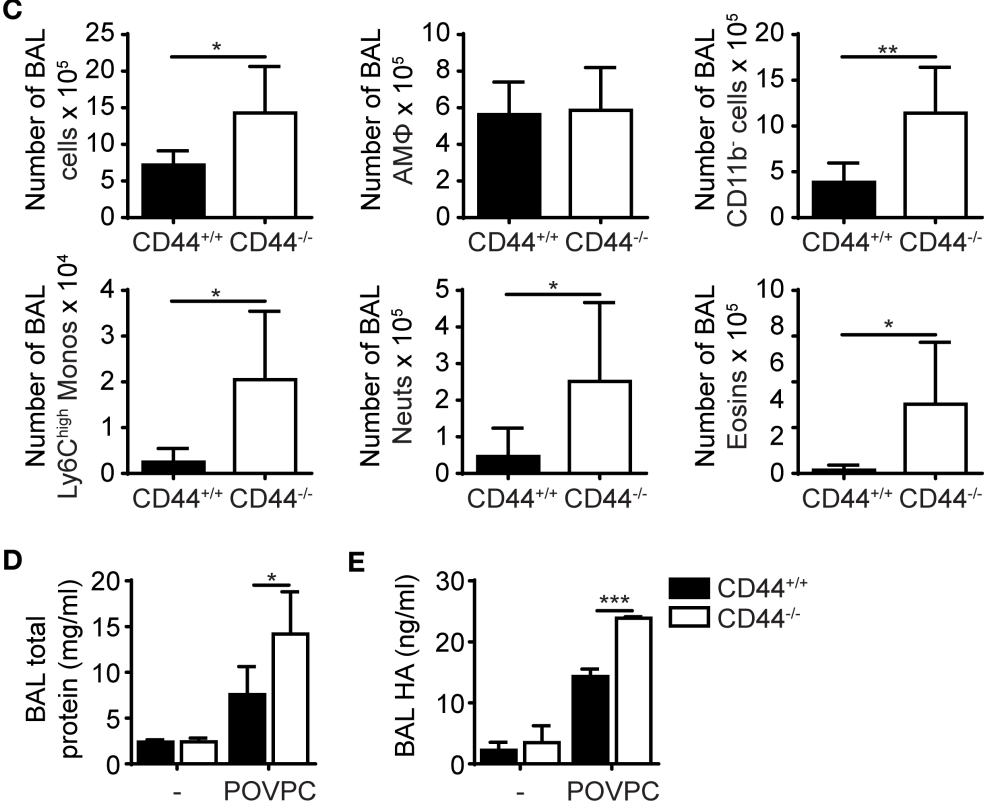

E
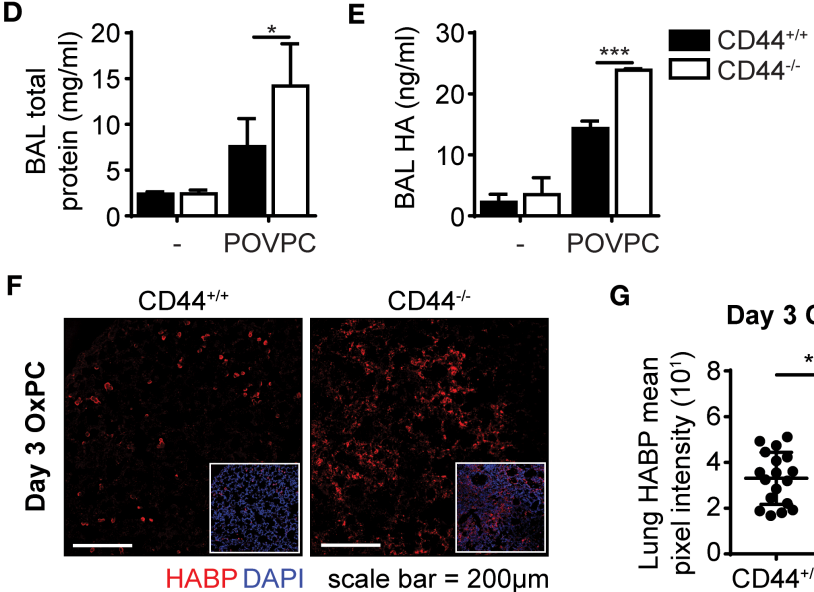

G

Day 3 OxPC

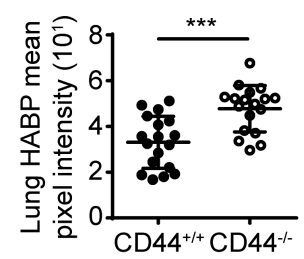

FIGURE 5 | POVPC induced pulmonary inflammation is exacerbated in CD44-/- mice. (A) Percent weight change over 3 days from CD44 $4^{+/+}$and $C D 44^{-/-}$mice treated with i.t. POVPC. (B) Representative flow cytometry plots showing the gating (after live/dead and sizing gating) and proportion of AMs, Ly6Chigh monocytes, neutrophils, eosinophils, and $\mathrm{CD} 11 \mathrm{~b}^{-}$cells in the BAL of $\mathrm{CD} 44^{+/+}$and $\mathrm{CD} 44^{-/-}$mice 3 days after POVPC instillation. (C) Graphs comparing the number of total BAL 
FIGURE 5 | cells, AMs, CD11b- cells, Ly6c high monocytes, neutrophils, and eosinophils in the BAL of CD44+/+ and CD44-/- mice 3 days after POVPC instillation (D) Level of total protein in the BAL supernatant of CD44+/+ and CD44-/- mice treated with or without POVPC measured by BCA. (E) Level of HA in the BAL of CD44 ${ }^{+/+}$and $C D 44^{-/-}$mice treated with or without POVPC measured by ELISA. (F) Confocal microscopy and (G) graphs comparing HABP mean pixel intensity from $\mathrm{CD}_{4} 4^{+/+}$and $\mathrm{CD} 44^{-/-}$lung sections at 3 days after POVPC treatment. Data show an average of two experiments \pm SD, each with three to five CD44 $4^{+/+}$and CD44 ${ }^{-/-}$mice. Data from confocal microscopy are pooled from $18 \mathrm{CD} 44^{+/+}$and CD44 ${ }^{-/-}$POVPC lung sections, from two experiments each with three to five mice. Significance indicated as ${ }^{*} p<0.05,{ }^{* \star} p<0.01,{ }^{\star \star *} p<0.001$, non-paired Student's $t$-test and (G only) Welch's $t$-test with Welch's correction.

AMs, we performed short-term adoptive transfer of CD44-/AMs into the alveolar space of $\mathrm{CD} 44^{+/+}$mice and vice versa. CD $44^{-/-}$AMs expressing the CD45.2 allele, were instilled into the trachea of CD44 $1++$ BoyJ mice expressing the CD45.1 allele and the BAL analyzed 7 days later (Figure 6A). After being transferred to a normal alveolar environment, the CD45.2 ${ }^{+}$ CD44-/- AMs decreased expression of CD36 (Figures 6B,C), consistent with CD36 expression responding to the reduced lipid surfactant environment of the $\mathrm{CD} 44^{+/+}$mice and indicative of an extrinsic effect. However, BODIPY, SSC-A and CD11c levels did not drop significantly, suggesting an intrinsic defect. In contrast, when CD $45.1^{+} \mathrm{CD} 44^{+/+} \mathrm{AMs}$ were transferred into the trachea of the CD45.2 $2^{+} \mathrm{CD} 44^{-/-}$mice and analyzed 7 days later (Figure 6D), these AMs dramatically increased CD36 expression, to levels higher than the $\mathrm{CD} 44^{-/-}$AMs (Figures 6E,F). In addition, SSC-A and BODIPY levels increased to similar levels observed in $\mathrm{CD} 44^{-/-} \mathrm{AMs}$, consistent with the wild-type cells responding to extrinsic changes in lipid surfactant levels in the lungs of $\mathrm{CD} 44^{-/-}$mice. To evaluate if the $\mathrm{CD} 44^{+/+}$AMs were directly responding to increased lipid levels in the lung surfactant of CD $44^{-/-}$mice, ex vivo CD $44^{+/+}$ AMs were incubated with PC for $48 \mathrm{~h}$ in vitro then analyzed for neutral lipids using BODIPY, and CD36 expression. Both showed a significant increase in $\mathrm{CD} 44^{+/+}$AMs (Figures 6G-I), demonstrating a direct response to extrinsic changes in extracellular PC. Together, these data suggest both intrinsic and extrinsic defects affect CD44 ${ }^{-/}$AMs, which impact intracellular lipid levels and CD36 expression, respectively.

To further evaluate the defects in $\mathrm{CD} 44^{-/-}$AMs, we performed bone marrow reconstitution experiments on irradiated mice. We reconstituted irradiated CD $45.1^{+} \mathrm{CD} 44^{+/+}$ mice with $\mathrm{CD} 45.2^{+} \mathrm{CD} 44^{-/-}$bone marrow (Figure 7A). After allowing several weeks for reconstitution of the AM compartment, $\mathrm{CD} 44^{-/-}$AMs were isolated from the BAL and had a similar phenotype to $\mathrm{CD} 44^{-/-}$AMs isolated from CD $44^{-/-}$mice, namely similar levels of BODIPY, CD36 and $\mathrm{CD} 11 \mathrm{c}$ (Figures $7 \mathbf{B}, \mathbf{C}$ ). We also reconstituted irradiated $\mathrm{CD} 44^{+/+}$mice with $50 \% \mathrm{CD} 44^{+/+}$and $50 \% \mathrm{CD} 44^{-/-}$bone marrow and analyzed both $\mathrm{CD} 44^{+/+}$and $\mathrm{CD} 44^{-/-}$AMs from the same lung environment after allowing at least 7 weeks for reconstitution of the lung macrophage compartment (Figure 7D). This competitive transfer leads to the dominance of $\mathrm{CD} 44^{+/+} \mathrm{AMs}$ over $\mathrm{CD} 44^{-/-}$AMs in an 80:20 ratio, as CD44-/- AMs are less able to survive (12). Analysis of both the $\mathrm{CD} 44^{+/+}$and $\mathrm{CD} 44^{-/-}$AMs from the same mice showed that the CD44-/- AMs were significantly higher in SSC and CD11c levels (Figure 7E), indicative of an intrinsic defect. Together, these results show the ability of $\mathrm{CD} 44^{-/-}$AMs to regulate CD36 expression in response to changes in the lung environment, but an inability to decrease their lipid content or reduce CD11c levels, indicating both cell extrinsic and intrinsic changes in CD44-/- AMs.

\section{CSF-2 Partially Restored Lipid Surfactant Homeostasis in CD44-/- BAL but Did Not Reduce Lipid Droplets in CD44-/- AMs}

While the reduced numbers of $\mathrm{CD} 44^{-/-}$AMs (12) could contribute to increased PC and cholesterol levels in the BAL, the adoptive transfer and competitive reconstitution experiments suggested an intrinsic defect in the ability to catabolize lipids in the $\mathrm{CD} 44^{-/-} \mathrm{AMs}$, which was also supported by the lipidomic data. Lipid droplet accumulation and the foamy AM phenotype is a feature of immature AMs that arise after the deletion of CSF-2, PPAR $\gamma$ or TGF $\beta$, which are important for maturation and survival (2-5). While the RNAseq data showed reduced TGF 32 transcript levels in $\mathrm{CD} 44^{-/-} \mathrm{AMs}$, these transcripts were very low compared to the levels of TGF $\beta 1$ transcripts, which did not differ between normal and CD44 ${ }^{-/-}$AMs (geo accession no: GSE138445). CSF-2 induces PPAR $\gamma$ expression (4) and upregulates CD11c expression in bone marrow derived macrophages (12), and both CSF-2 and PPAR $\gamma$ agonists promote CD44-mediated HA binding (12). It is possible that some of the downstream effects of CSF-2 or PPAR $\gamma$ could be mediated via CD44 and its interaction with HA, which then promotes AM survival (12). Since CSF-2 also attenuates bleomycin-induced lipid accumulation in the alveolar space (16), we determined if CSF-2 could rescue the defects in surfactant lipid homeostasis caused by CD44 deficiency. CSF-2 was given daily to the $\mathrm{CD} 44^{-/-}$mice by i.t. for 7 days, then the BAL from the mice was analyzed. While CSF-2 instillation did not significantly alter the composition of cells in the BAL (Figure 8A), it did increase CD44- ${ }^{-/-}$AM numbers (Figure 8B) and decrease the concentration of PC in the BAL (Figure 8C). There was a concomitant reduction in CD36 expression in the $\mathrm{CD} 44^{-/-}$AMs, but no significant changes were observed in their granularity (SSC-A), neutral lipid content (measured by BODIPY), or the expression of CD11c (Figures 8D,E). This suggests that the reduced number of AMs contributes to increased lipid surfactant levels and concomitantly, increased levels of CD36. However, CSF-2 does not rescue the cell intrinsic defect of accumulated lipids in CD $44^{-/-}$AMs.

\section{CD44-/- AMs Have Reduced PPAR $\gamma$ Expression}

PPAR $\gamma$ is an important transcriptional regulator of lipid metabolism (10) and this, coupled with its key role in AM maturation and survival (4), make it a potential candidate 

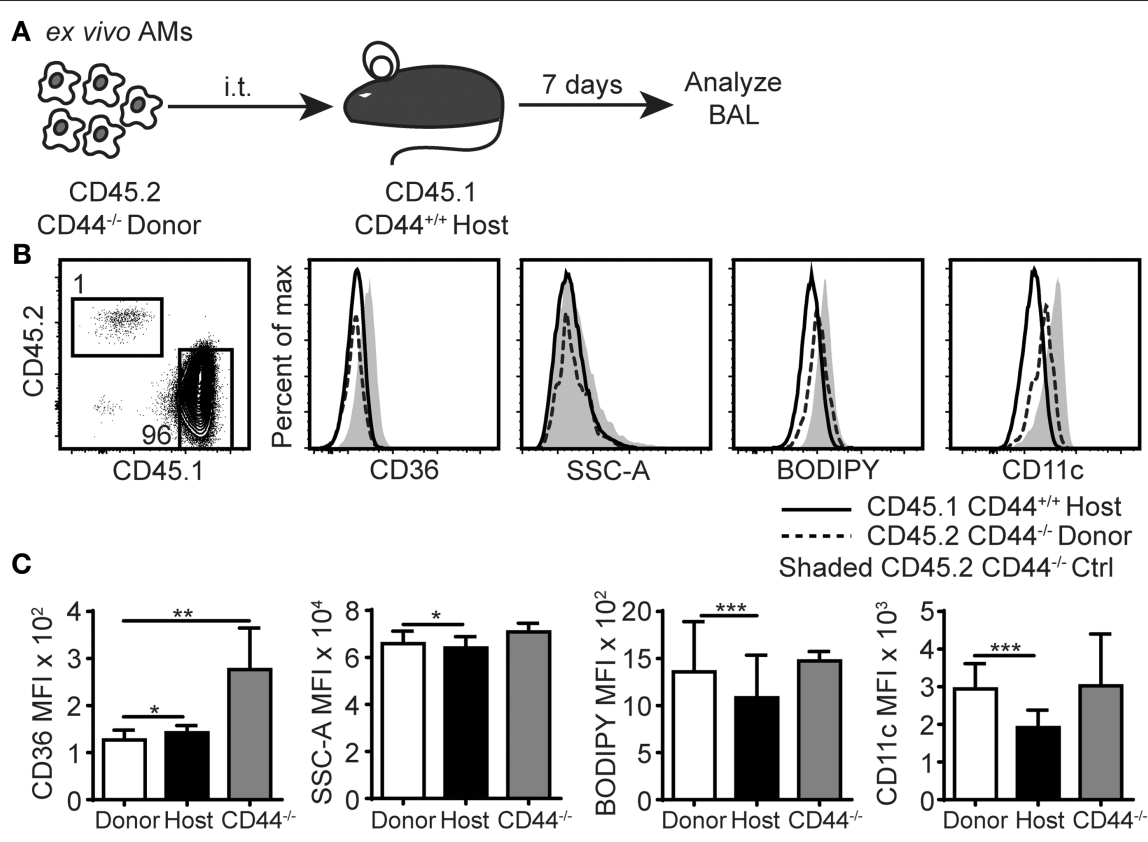

D

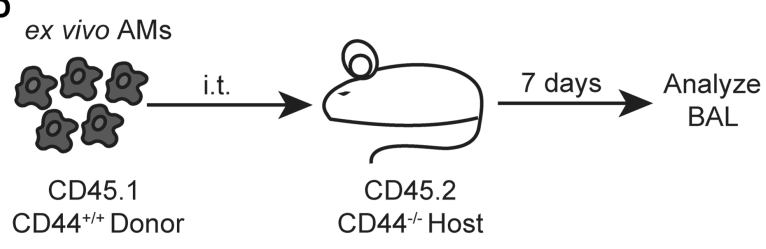

E
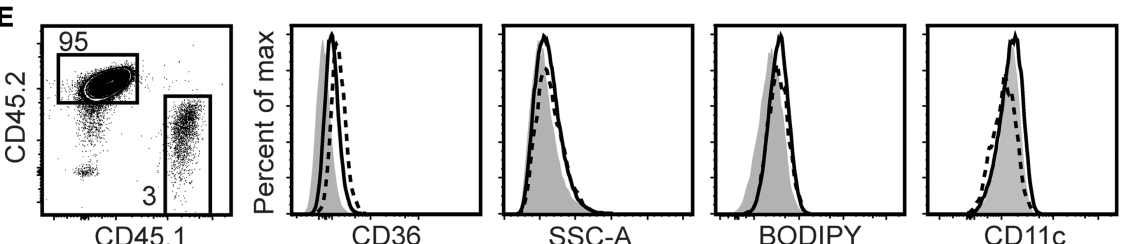

CD45.2 CD44 ${ }^{-/-}$Host

..... CD45.1 CD44 ${ }^{+/+}$Donor

$\mathbf{F}$ Shaded CD45.1 CD44 ${ }^{+/+} \mathrm{Ctrl}$

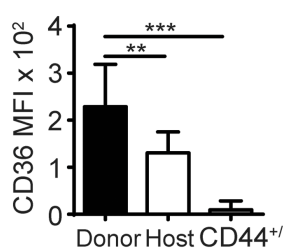

G
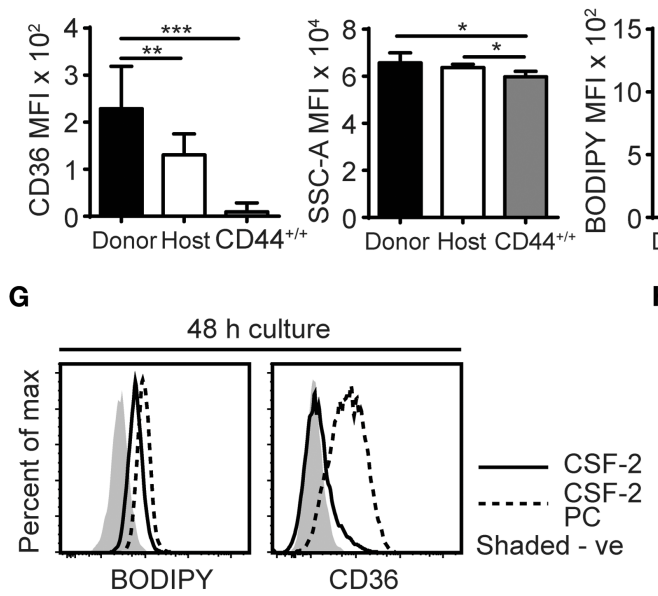

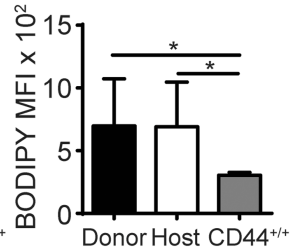

H

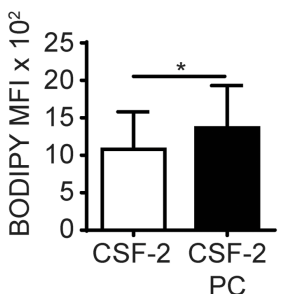

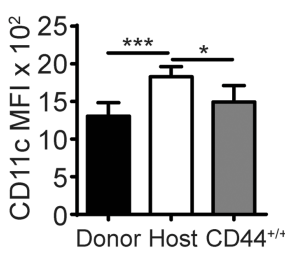

I

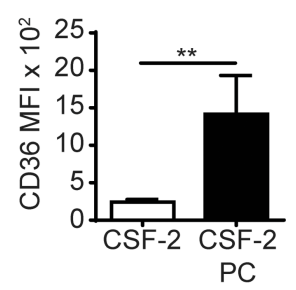

FIGURE 6 | AMs lipid homeostasis is controlled by the extracellular milieu and the expression of CD44. (A) Schematic diagram showing donor AMs isolated from $\mathrm{CD} 45.2^{+} \mathrm{CD} 44^{-/-}$mice are transferred by i.t. into $\mathrm{CD} 45.1^{+} \mathrm{CD} 44^{+/+}$host mice and analyzed 7 days later. (B) Representative flow cytometry plots comparing the

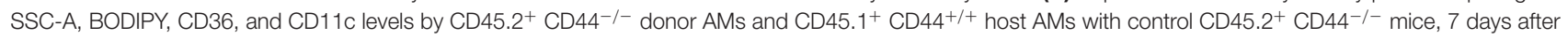




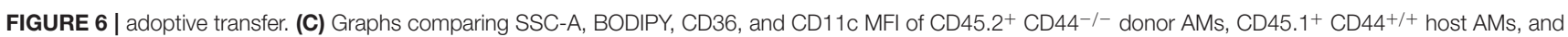
ex vivo CD44-/- AMs. (D) Schematic diagram showing donor AMs isolated from CD45.1+ CD44+/+ mice are transferred by i.t. into $\mathrm{CD} 45.2^{+} \mathrm{CD} 44^{-/-}$host mice and analyzed 7 days later. (E) Representative flow cytometry plots comparing the SSC-A, BODIPY, CD36, and CD11c levels in CD45.1+ CD44+/+ donor AMs and CD 45.2+ CD44-/- host AMs compared with CD45.1+ CD44+/+ control mice, 7 days after adoptive transfer. (F) Graphs comparing SSC-A, BODIPY, CD36, and $\mathrm{CD} 11 \mathrm{c} \mathrm{MFI}$ of $\mathrm{CD} 45.1^{+} \mathrm{CD} 44^{+/+}$donor AMs, CD45.2 $2^{+} \mathrm{CD} 44^{-/-}$host $\mathrm{AMs}$, and ex vivo CD44+/+ $\mathrm{AMs}$. (G) Representative flow cytometry histograms comparing the BODIPY and CD36 MFI of AMs after $48 \mathrm{~h}$ culture in CSF- 2, or CSF-2 and PC. (H,I) Graphs comparing BODIPY labeling and CD36 expression by AMs cultured in CSF-2, or CSF-2 and PC for $48 \mathrm{~h}$. For adoptive transfer experiments, data show an average of two experiments \pm SD, each with three to five mice. Significance indicated as ${ }^{*} p<0.05,{ }^{* *} p<0.01,{ }^{* * *} p<0.001$, paired (donor AMs vs. host AMs) and non-paired Student's $t$-test (CD44 ${ }^{-/-}$donor AMs vs. ex vivo CD44 ${ }^{-/-}$AMs or CD44 $4^{-1}$ host AMs vs. ex vivo CD44 ${ }^{+/+}$AMs). For in vitro cell culture experiments, data show an average of two experiments $\pm S D$, each with three to five mice. Significance indicated as ${ }^{\star} p<0.05,{ }^{* *} p<0.01,{ }^{\star \star *} p<0.001$, paired Student's $t$-test.

for contributing to the cell intrinsic defects present in the $\mathrm{CD} 44^{-/-}$AMs. Although no differences in PPAR $\gamma$ transcript levels were apparent from the RNAseq data, other forms of regulation such as PPAR $\gamma$ activation, cellular localization, or protein levels may be defective in $\mathrm{CD} 44^{-/-}$AMs. Confocal microscopy showed that the majority of $\operatorname{PPAR} \gamma$ in ex vivo $\mathrm{CD} 44^{+/+}$and $\mathrm{CD} 44^{-/-} \mathrm{AMs}$ was localized to the nucleus (Figure 9A). Both confocal microscopy and flow cytometry showed PPAR $\gamma$ protein was expressed at a slightly lower level in $\mathrm{CD} 44^{-/-}$AMs (Figures 9B,C). To determine if this was of functional significance, ex vivo $\mathrm{CD} 44^{+/+}$AMs were incubated for $48 \mathrm{~h}$ in the presence of CSF- 2 and treated with a selective PPAR $\gamma$ antagonist, T-0070907 (43), to mimic conditions in the CD44-/- AMs. The antagonist increased the levels of BODIPY, as well as CD36 and CD11c (Figures 9D,E). This suggests that the reduced expression/activation of PPAR $\gamma$ could contribute to the accumulation of lipids in $\mathrm{CD} 44^{-/-}$AMs.

\section{DISCUSSION}

AMs play an important role in maintaining lung homeostasis and are responsible for the uptake of surfactant and oxidized surfactant lipids, their storage and catabolism (1). Here we report that CD44 deficiency disrupted lipid surfactant homeostasis in the alveolar space and led to intracellular lipid accumulation in AMs. CD44-/- AMs accumulated PC and cholesterol and had increased intracellular lipid droplets, giving the AMs a foamy appearance, with increased side scatter (SSC) and autofluorescence. CD44 deficiency in AMs led to the differential expression of 200 genes, several of which were involved in lipid metabolism and trafficking. The inability of $\mathrm{CD} 44^{-/-} \mathrm{AMs}$ to reduce intracellular lipid levels coupled with the reduced numbers of AMs in CD44-/- mice resulted in the increase in lung surfactant lipids in the BAL supernatant. The inability to reduce intracellular lipid accumulation in $\mathrm{CD} 44^{-/-}$AMs may be attributed, at least in part, to the dysregulation of PPAR $\gamma$.

Transcriptional analysis of $\mathrm{CD} 44^{+/+}$and $\mathrm{CD} 44^{-/-}$AMs identified the upregulation of genes involved in cholesterol efflux and trafficking in CD44 $4^{-/-}$AMs. These included ApoE (39), which was validated by qPCR (data not shown) and $A B C A 1$ (40), key genes downstream of PPAR $\gamma$ signaling. Although $C D 36$ gene levels were not significantly different by transcriptomic analysis, cell surface expression of CD36 was increased in $\mathrm{CD} 44^{-/-} \mathrm{AMs}$, and this correlated with extracellular lipid levels. CD36 is a multi-functional scavenger receptor that binds oxidized lipids and fatty acids (37) and CD36 signaling promotes cholesterol efflux and inhibits cholesterol synthesis by activating PPAR $\gamma(44)$. The transcriptional analysis also predicted the down regulation of several genes in $\mathrm{CD} 44^{-/-} \mathrm{AMs}$, including srebf2, a master transcriptional regulator of cholesterol and fatty acid synthesis $(38,45)$ and a cluster of genes associated with sterol/cholesterol synthesis. Together, these data suggest that $\mathrm{CD} 44^{-/-} \mathrm{AMs}$ are responding to increased exposure to lipids by activating gene pathways responsible for reducing lipid content, yet are still unable to reduce intracellular lipid content. Although PPAR $\gamma$ is a master transcriptional regulator of lipid metabolism (8$10)$, its effects can be cell-type specific and complicated by the activation of its heterodimeric partner, RXR and other lipid regulated transcription factors such as LXR. While one may have predicted that PPAR $\gamma$ would have been more active in CD44 ${ }^{-/-}$AMs, transcript levels were not different and slightly less, not more, PPAR $\gamma$ protein levels were found in the nucleus of CD $44^{-/-}$AMs.

In AMs, PPAR $\gamma$ expression is induced by CSF- 2 and TGF $\beta$ and is critical for their development (4). PPAR $\gamma$ upregulates genes important for the transcriptional identity of AMs, including molecules involved in the intracellular binding, storage and metabolism of lipids, which help prevent foam-cell formation and protect against lipotoxicity $(4,9,10,46)$. PPAR $\gamma$ deficiency in AMs causes significant accumulation of cholesterol and phospholipids in the BAL supernatant $(47,48)$ and leads to immature AMs that have increased lipid droplets (4). This is consistent with the results here, where we found slightly reduced levels of PPAR $\gamma$ in the nucleus of $\mathrm{CD} 44^{-/-}$AMs. The upregulation of BODIPY ${ }^{+}$lipid droplets and CD36 on CD $44^{+/+}$ AMs after in vitro culture with a PPAR $\gamma$ antagonist also supports the idea that reduced PPAR $\gamma$ activity mimics the $\mathrm{CD} 44^{-/-}$AM phenotype. However, in addition to lipid induced activation of $\operatorname{PPAR} \gamma$, its activity can also be regulated at the translational and protein level. PPAR $\gamma$ protein is degraded via ubiquitination after ligand mediated activation (49), and so it is possible that $\mathrm{CD} 44^{-/-}$AMs have lower nuclear PPAR $\gamma$ levels because they have been exposed to greater levels of activating PPAR $\gamma$ ligands, leading to greater degradation.

Whether CD44 directly or indirectly modulates PPAR $\gamma$ activity remains to be addressed. In IL- $1 \beta$ stimulated chondrosarcoma cells, the addition of high molecular weight HA increases PPAR $\gamma$ expression at both the mRNA and protein level (50). It will be of interest to determine if there 
A

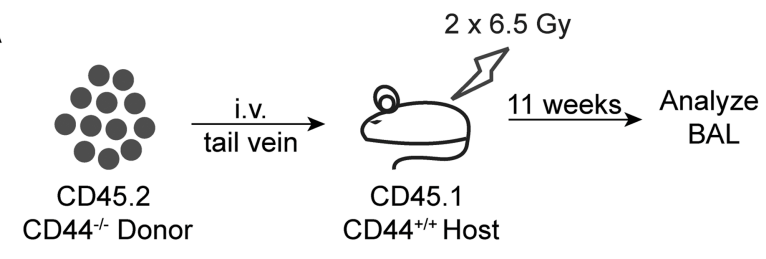

B

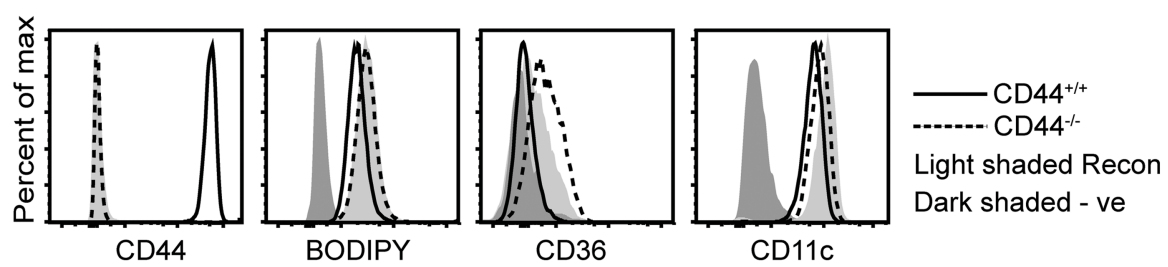

C

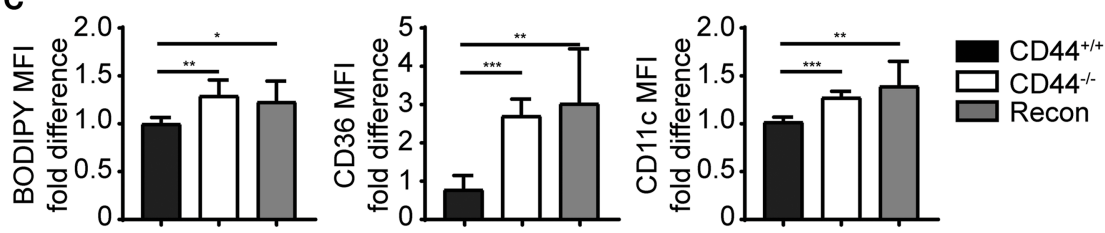

D

CD45.1 x CD45.2
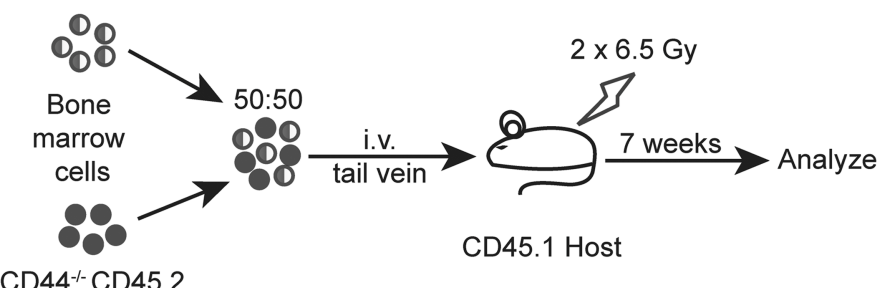

CD44-1- CD45.2

CD45.1 Host
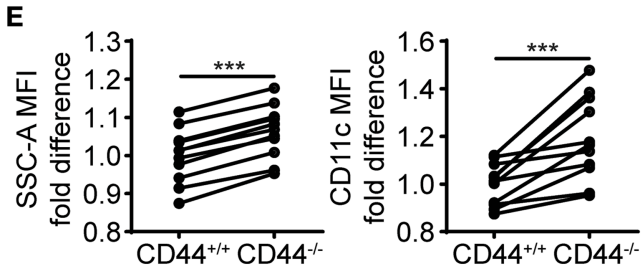

FIGURE 7 | Cell intrinsic defects in CD44-/- AMs are preserved after long term BM reconstitution. (A) Schematic showing the BM reconstitution experiment where BM cells from $\mathrm{CD}_{4} 4^{-/-}$mice were injected into lethally irradiated $\mathrm{CD} 44^{+/+}$host mice and analyzed 11 weeks later. (B) Representative flow cytometry plots comparing the CD44, BODIPY, CD36, and CD11c levels of AMs from CD44 $/ /+$ mice and CD44-/- mice, as well CD44-/- AMs reconstituted in CD44 comparing the fold difference of BODIPY, CD36, and CD11C of AMs from CD44 ${ }^{+/+}$mice and $\mathrm{CD} 44^{-/-}$mice, as well CD44 ${ }^{-/-}$AMs reconstituted in $\mathrm{CD} 44^{+/+}$mice. (D) Schematic showing the BM reconstitution experiment where BM cells from $\mathrm{CD} 44^{+/+}$and $\mathrm{CD} 44^{-/-}$mice were injected at equal proportions into lethally irradiated host mice to study the role of CD44 in AM repopulation. (E) Graphs comparing the fold difference in the granularity (SSC-A) and CD11c between CD44+/+ and CD44-/- AMs in the BAL after 7 weeks in competition, as measured by flow cytometry. Data show an average of two experiments $\pm S D$, each with three to five mice. Significance indicated as ${ }^{*} p<0.05,{ }^{* \star} p<0.01,{ }^{* \star *} p<0.001$ unpaired Student's $t$-test.

is a link between HA engagement by CD44 and PPAR $\gamma$ levels or activation. Alternatively, TGF $\beta$ can upregulate PPAR $\gamma$ expression (4) and RNAseq data did predict a reduction in TGF 32 expression in CD44-/- AMs, although not for the more highly expressed TGF $\beta 1$. In other cell types, CD44 and HA-binding modulate TGF $\beta$ responses by facilitating TGF $\beta$ cleavage and activation (51), or by promoting TGF $\beta$ receptor signaling (52).

Mice deficient in CSF-2, or harboring an AM-specific deletion of PPAR $\gamma$, or the conditional deletion of TGF $\beta R 2$, all produce $\mathrm{CD} 1 \mathrm{~b}^{+}$immature foamy macrophages, which are unable to regulate lipid turnover leading to surfactant accumulation in the BAL and ultimately PAP (3-5). Their immature $\mathrm{CD}_{11} \mathrm{~b}^{+} \mathrm{CD} 11 \mathrm{c}^{\text {low }}$ Siglec $\mathrm{F}^{\text {low }}$ phenotype is distinct from the phenotype of CD44-/- AMs, which have high levels of mature AM markers: Siglec F, CD11c, CD206, CD200R, and Sirp $\alpha$. However, CD44 $4^{-/}$AMs also express low levels of $\mathrm{CD} 11 \mathrm{~b}$ and $\mathrm{MHCII}$, and RNAseq analysis predicted an upregulation of $m a f B$, a transcription factor that is normally down-regulated in mature cells, to allow self-renewal and 


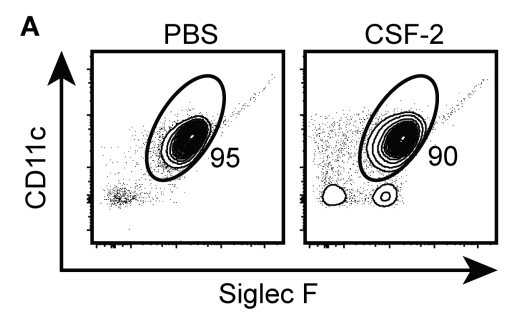

D

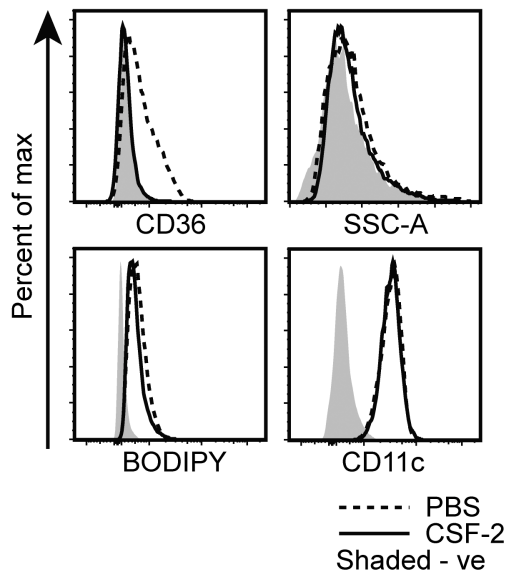

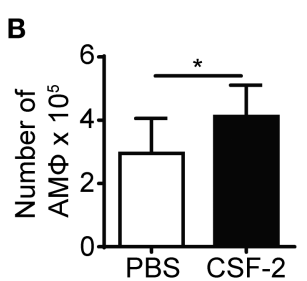

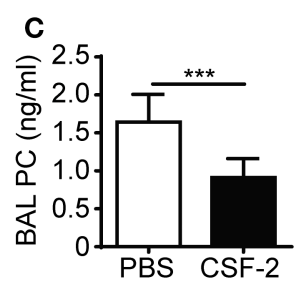

E
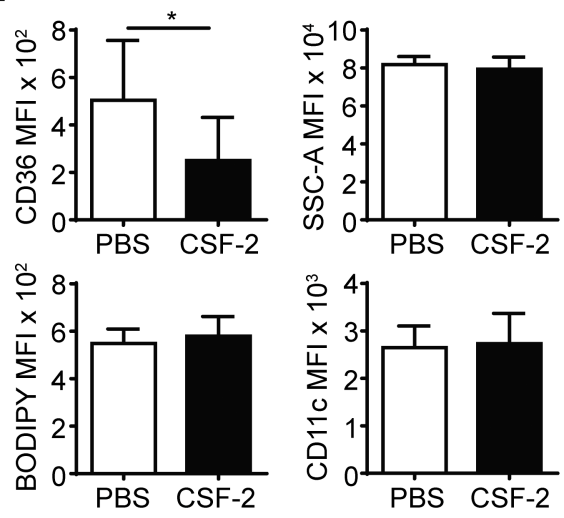

FIGURE 8 | CSF-2 induces AM proliferation and rescues aberrant pulmonary surfactant PC accumulation in CD44-/- mice. (A) Representative flow cytometry plots showing the proportion of BAL AMs from CD44-/- mice after 7 days of PBS or CSF-2 treatment. (B) Number of AMs in the BAL from CD44-/- mice after PBS or CSF-2 treatment. (C) BAL PC concentration from CD44-1- mice after PBS or CSF-2 treatment. (D) Representative flow cytometry histograms comparing the phenotype of AMs from CD44-/- mice after 7 days of PBS or CSF-2 treatment. (E) Graphs comparing the MFI of SSC-A, BODIPY, CD36, and CD11C between AMs from $\mathrm{CD}_{4} 4^{-1-}$ mice after 7 days of PBS or CSF-2 treatment. Data show an average of two experiments \pm SD, each with three to five mice. Background MFI of autofluorescence from unlabeled $\mathrm{CD} 44^{+/+}$and $\mathrm{CD} 44^{-/-}$cells were, respectively, subtracted in the flow cytometry analysis. Significance indicated as ${ }^{*} p<0.05$, ${ }^{\star \star *} p$ $<0.001$, non-paired Student's t-test.

terminal differentiation (53). It is possible some of the effects of CSF-2 on AMs maybe mediated by CD44 as CSF-2 induces HA binding by CD44 and this is known to promote the survival of AMs (12). Although exogenous CSF-2 restored $\mathrm{AM}$ numbers and reduced PC levels in the BAL of $\mathrm{CD} 44^{-/-}$ mice, it did not impact the intracellular lipid accumulation in CD44-/- AMs.

RNAseq predicted the altered expression of genes involved in cholesterol/sterol synthesis and trafficking, triglyceride synthesis and phospholipid catabolism in $\mathrm{CD} 44^{-/-}$AMs. This suggested dysregulation of lung lipid surfactant metabolism in CD $44^{-/-}$ AMs, which was validated by measuring the lipids present in the BAL supernatant and cell pellet of the $\mathrm{CD} 44^{+/+}$and CD44-/- mice. Although the molecular composition of lung surfactant has been analyzed in young and old mice (54), to our knowledge, this study is the first to provide a full lipidomic analysis of the lung surfactant and AMs. The major lipids present in lung surfactant include PC moieties (1, 7, 11 ), which were elevated in the $\mathrm{CD} 44^{-/-} \mathrm{BAL}$ supernatant and cell pellet. Lipidomic MS analysis of the cell pellets from CD44 ${ }^{+/+}$and CD44 ${ }^{-/}$AMs showed greater accumulation of intracellular lipids including PC, PE, PG, fatty acids, cholesterol, and OxPLs in CD44 $4^{-/-}$AMs. These results were consistent with the observations from flow cytometry and confocal microscopy experiments which showed CD44-/- AMs had higher BODIPY labeled neutral lipids and OxPC levels than CD44 ${ }^{+/+}$AMs. The increased cytotoxicity of OxPC in CD44-/- AMs coupled with the observed increase in ROS and OxPC levels in these cells, resulted in an increased inflammatory response in the lungs of $\mathrm{CD} 44^{-/-}$mice exposed to oxidized lipids. This is of significance as oxidized lipids propagate an inflammatory response. Interestingly, mice exposed to bleomycin generate oxidized lipids (16) and CD44-/- mice have significantly worse bleomycin-induced inflammation and lung damage compared to wild-type mice (28).

Overall, this work demonstrates a new role for CD44 in AMs in maintaining lipid surfactant homeostasis, a key function of AMs in the alveolar space. Dysregulation of lipid surfactant homeostasis in $\mathrm{CD} 44^{-/-} \mathrm{AMs}$ leads to a buildup of lipid surfactant and foamy AMs, and an increase in oxidized lipids exacerbates lung damage and inflammation. This work also raises the possibility that reduced numbers of AMs and compromised lipid surfactant metabolism, leading to increased lung damage and inflammation, are contributing factors to the development of secondary pulmonary alveolar proteinosis. 
A

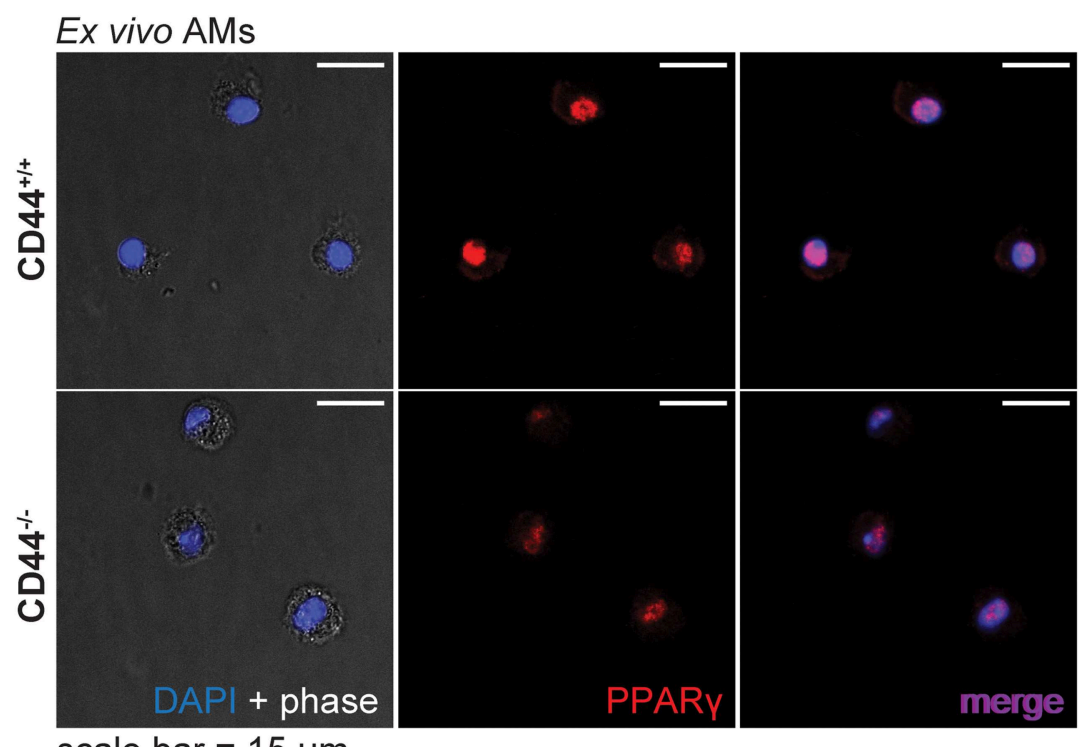

B
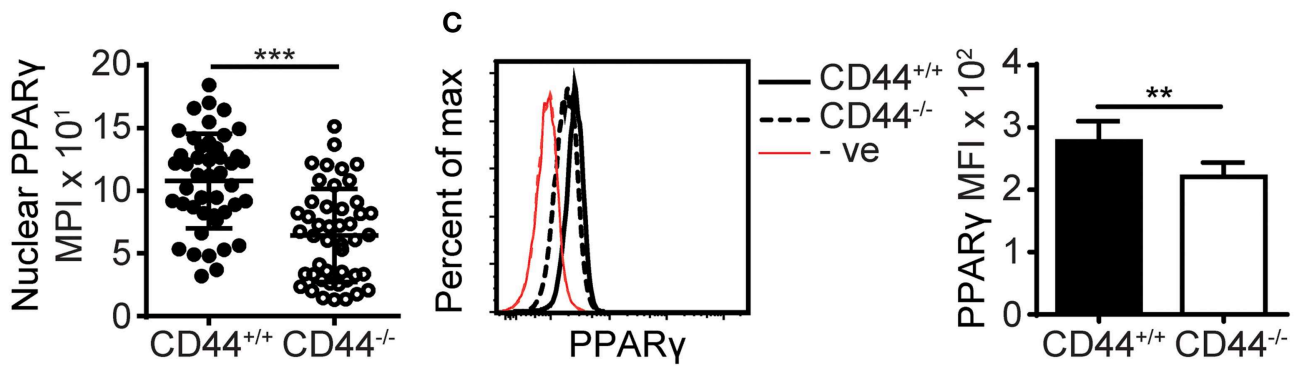

D
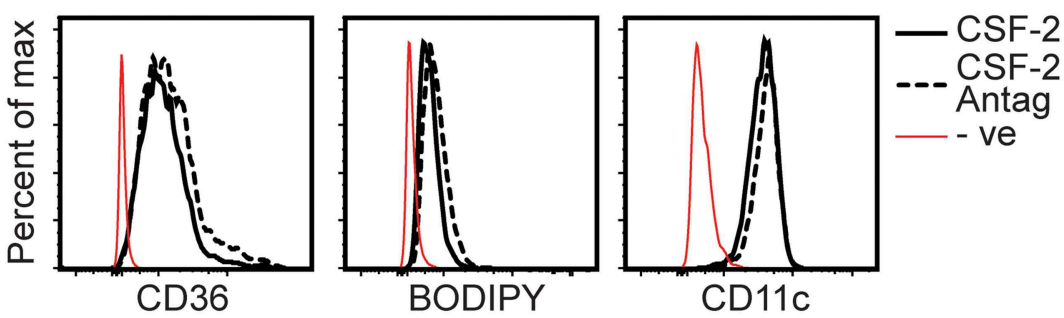

$\mathbf{E}$
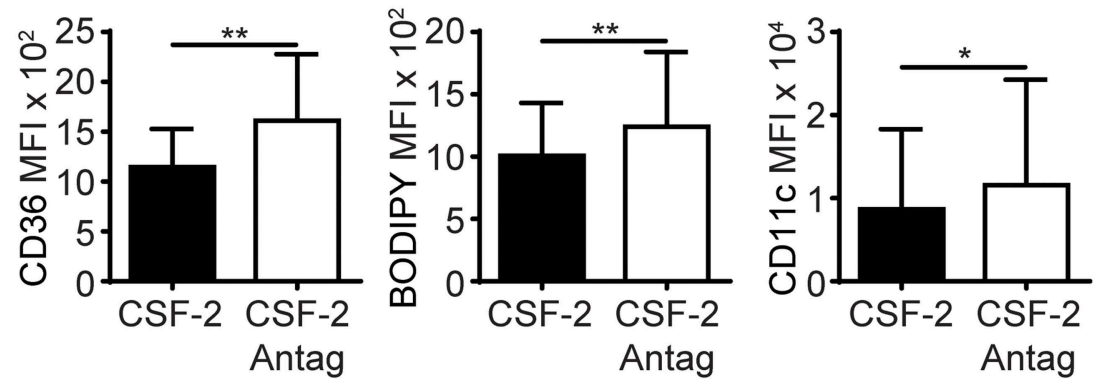

FIGURE 9 | PPAR $\gamma$ expression is defective in CD44 $4^{-/-}$AMs. (A) Representative confocal microscopy showing CD44 $4^{+/+}$and CD44 $4^{-/-}$AMs labeled with intracellular PPAR $\gamma$ antibody and DAPI. (B) Comparison of nuclear PPAR $\gamma$ mean pixel intensity (MPI) between CD44 ${ }^{+/+}$and CD44-/- AMs, determined by confocal microscopy. (C) Representative flow cytometry histograms and graphs comparing intracellular PPAR $\gamma$ expression between CD44 $4^{+/+}$and CD44 $4^{-/-}$AMs. (D,E) Representative flow cytometry histograms and graphs comparing the levels of CD36, BODIPY and CD11c levels by MFI (after subtraction of background autofluorescence) in CD44 ${ }^{+/+}$ AMs cultured with CSF-2 or CSF-2 and the PPAR $\gamma$ antagonist T0070907 (Antag) for $48 \mathrm{~h}$ in culture. Data show an average of three to five mice from each experiment $\pm \mathrm{SD}$, repeated twice or three times; for confocal imaging three to four fields containing cells were analyzed per mice. Significance indicated as ${ }^{*} p<0.05,{ }^{* *} p<0.01$, ${ }^{* * *} p<0.001$, non-paired Student's $t$-test. 


\section{DATA AVAILABILITY STATEMENT}

The datasets generated for this study can be found in the Geo database \& SRA. GEO accession number: GSE138445.

\section{ETHICS STATEMENT}

The animal study was reviewed and approved by the University of British Columbia Animal Care Committee.

\section{AUTHOR CONTRIBUTIONS}

YD initiated and developed the project and performed most of the experiments. AA, ZH, JG, GP, and SL-S provided input and performed experiments. MD provided technical support. CR provided supervision. TH oversaw the lipidomic experiments, provided financial support, and supervision. PJ developed and oversaw the project, provided supervision, and acquired funds. YD and PJ wrote the manuscript, with contributions from JG, which was reviewed by all authors.

\section{REFERENCES}

1. Hussell T, Bell TJ. Alveolar macrophages: plasticity in a tissue-specific context. Nat Rev Immunol. (2014) 14:8-93. doi: 10.1038/nri3600

2. Guilliams M, De Kleer I, Henri S, Post S, Vanhoutte L, De Prijck S, et al. Alveolar macrophages develop from fetal monocytes that differentiate into long-lived cells in the first week of life via GM-CSF. J Exp Med. (2013) 210:1977-92. doi: 10.1084/jem.20131199

3. Shibata Y, Berclaz PY, Chroneos ZC, Yoshida M, Whitsett JA, Trapnell BC. GM-CSF regulates alveolar macrophage differentiation and innate immunity in the lung through PU.1. Immunity. (2001) 15:557-67. doi: 10.1016/S1074-7613(01)00218-7

4. Schneider C, Nobs SP, Kurrer M, Rehrauer H, Thiele C, Kopf M. Induction of the nuclear receptor PPAR-gamma by the cytokine GM-CSF is critical for the differentiation of fetal monocytes into alveolar macrophages. Nat Immunol. (2014) 15:1026-37. doi: 10.1038/ni.3005

5. Yu X, Buttgereit A, Lelios I, Utz SG, Cansever D, Becher B, et al. The cytokine TGF-beta promotes the development and homeostasis of alveolar macrophages. Immunity. (2017) 47:903-12.e4. doi: 10.1016/j.immuni.2017.10.007

6. Trapnell BC, Carey BC, Uchida K, Suzuki T. Pulmonary alveolar proteinosis, a primary immunodeficiency of impaired GM-CSF stimulation of macrophages. Curr Opin Immunol. (2009) 21:514-21. doi: 10.1016/j.coi.2009.09.004

7. Trapnell BC, Nakata K, Bonella F, Campo I, Griese M, Hamilton J, et al. Pulmonary alveolar proteinosis. Nat Rev Dis Primers. (2019) 5:16. doi: 10.1038/s41572-019-0066-3

8. Schoonjans K, Staels B, Auwerx J. Role of the peroxisome proliferatoractivated receptor (PPAR) in mediating the effects of fibrates and fatty acids on gene expression. J Lipid Res. (1996) 37:907-25.

9. Tontonoz P, Spiegelman BM. Fat and beyond: the diverse biology of PPARgamma. Annu Rev Biochem. (2008) 77:289-312. doi: 10.1146/annurev.biochem.77.061307.091829

10. Ahmadian M, Suh JM, Hah N, Liddle C, Atkins AR, Downes M, et al. PPARgamma signaling and metabolism: the good, the bad and the future. Nat Med. (2013) 19:557-66. doi: 10.1038/nm.3159

11. Vangolde LMG, Batenburg JJ, Robertson B. The pulmonary surfactant system - biochemical aspects and functional-significance. Physiol Rev. (1988) 68:374455. doi: 10.1152/physrev.1988.68.2.374

12. Dong Y, Poon GFT, Arif AA, Lee-Sayer SSM, Dosanjh M, Johnson P. The survival of fetal and bone marrow monocyte-derived alveolar macrophages

\section{FUNDING}

This work was supported by grants from the Natural Sciences and Engineering Research Council of Canada (NSERC) and the Canadian Institutes of Health Research (MOP 119503, PJT-153455) to PJ and UBC startup grant (F18-03001) and Canadian Foundation for Innovation (38159) to TH. AA and YD acknowledge fellowships from NSERC and UBC, respectively.

\section{ACKNOWLEDGMENTS}

We acknowledge invaluable assistance from the UBC Animal and Flow cytometry Facilities, as well as excellent service from the BRC-Seq Next-Gen sequencing core.

\section{SUPPLEMENTARY MATERIAL}

The Supplementary Material for this article can be found online at: https://www.frontiersin.org/articles/10.3389/fimmu. 2020.00029/full\#supplementary-material

is promoted by CD44 and its interaction with hyaluronan. Mucosal Immunol. (2017) 11:60114. doi: 10.1038/mi.2017.83

13. Ghoneim HE, Thomas PG, McCullers JA. Depletion of alveolar macrophages during influenza infection facilitates bacterial superinfections. J Immunol. (2013) 191:1250-9. doi: 10.4049/jimmunol.1300014

14. Dagvadorj J, Shimada K, Chen S, Jones HD, Tumurkhuu G, Zhang W, et al. Lipopolysaccharide induces alveolar macrophage necrosis via CD14 and the P2X7 receptor leading to interleukin-1alpha release. Immunity. (2015) 42:640-53. doi: 10.1016/j.immuni.2015.03.007

15. Imai Y, Kuba K, Neely GG, Yaghubian-Malhami R, Perkmann T, van Loo $\mathrm{G}$, et al. Identification of oxidative stress and toll-like receptor 4 signaling as a key pathway of acute lung injury. Cell. (2008) 133:235-49. doi: $10.1016 /$ j.cell.2008.02.043

16. Romero F, Shah D, Duong M, Penn RB, Fessler MB, Madenspacher J, et al. A pneumocyte-macrophage paracrine lipid axis drives the lung toward fibrosis. Am J Respir Cell Mol Biol. (2015) 53:74-86. doi: 10.1165/rcmb.2014-0 3430C

17. Manoury B, Nenan S, Leclerc O, Guenon I, Boichot E, Planquois JM, et al. The absence of reactive oxygen species production protects mice against bleomycin-induced pulmonary fibrosis. Respir Res. (2005) 6:11. doi: 10.1186/1465-9921-6-11

18. Lamb NJ, Gutteridge JM, Baker C, Evans TW, Quinlan GJ. Oxidative damage to proteins of bronchoalveolar lavage fluid in patients with acute respiratory distress syndrome: evidence for neutrophil-mediated hydroxylation, nitration, and chlorination. Crit Care Med. (1999) 27:1738-44. doi: 10.1097/00003246-199909000-00007

19. Kirkham P, Rahman I. Oxidative stress in asthma and COPD: antioxidants as a therapeutic strategy. Pharmacol Ther. (2006) 111:476-94. doi: 10.1016/j.pharmthera.2005.10.015

20. Yoshimi N, Ikura Y, Sugama Y, Kayo S, Ohsawa M, Yamamoto $\mathrm{S}$, et al. Oxidized phosphatidylcholine in alveolar macrophages in idiopathic interstitial pneumonias. Lung. (2005) 183:109-21. doi: 10.1007/s00408-004-2525-0

21. Poon GF, Dong Y, Marshall KC, Arif A, Deeg CM, Dosanjh M, et al. Hyaluronan binding identifies a functionally distinct alveolar macrophagelike population in bone marrow-derived dendritic cell cultures. J Immunol. (2015) 195:632-42. doi: 10.4049/jimmunol.1402506

22. Culty M, O'Mara TE, Underhill CB, Yeager H Jr, Swartz RP. Hyaluronan receptor (CD44) expression and function in human peripheral blood monocytes and alveolar macrophages. J Leukoc Biol. (1994) 56:605-11. doi: 10.1002/jlb.56.5.605 
23. Johnson P, Arif AA, Lee-Sayer SSM, Dong Y. Hyaluronan and its interactions with immune cells in the healthy and inflamed lung. Front Immunol. (2018) 9:2787. doi: 10.3389/fimmu.2018.02787

24. Katoh S, Matsubara Y, Taniguchi H, Fukushima K, Mukae H, Kadota J, et al. Characterization of CD44 expressed on alveolar macrophages in patients with diffuse panbronchiolitis. Clin Exp Immunol. (2001) 126:545-50. doi: 10.1046/j.1365-2249.2001.01699.x

25. Pons AR, Noguera A, Blanquer D, Sauleda J, Pons J, Agusti AGN. Phenotypic characterisation of alveolar macrophages and peripheral blood monocytes in COPD. Eur Respir J. (2005) 25:647-52. doi: 10.1183/09031936.05.000 62304

26. Thepen T, Van Rooijen N, Kraal G. Alveolar macrophage elimination in vivo is associated with an increase in pulmonary immune response in mice. $J$ Exp Med. (1989) 170:499-509. doi: 10.1084/jem.170.2.499

27. Knapp S, Leemans JC, Florquin S, Branger J, Maris NA, Pater J, et al. Alveolar macrophages have a protective antiinflammatory role during murine pneumococcal pneumonia. Am J Resp Crit Care. (2003) 167:171-9. doi: 10.1164/rccm.200207-6980C

28. Teder P, Vandivier RW, Jiang D, Liang J, Cohn L, Pure E, et al. Resolution of lung inflammation by CD44. Science. (2002) 296:155-8. doi: 10.1126/science.1069659

29. Liang JR, Jiang DH, Griffith J, Yu S, Fan J, Zhao XJ, et al. CD44 is a negative regulator of acute pulmonary inflammation and lipopolysaccharideTLR signaling in mouse macrophages. J Immunol. (2007) 178:2469-75. doi: 10.4049/jimmunol.178.4.2469

30. Trapnell C, Hendrickson DG, Sauvageau M, Goff L, Rinn JL, Pachter L. Differential analysis of gene regulation at transcript resolution with RNA-seq. Nat Biotechnol. (2013) 31:46-53. doi: 10.1038/nbt.2450

31. Tripathi S, Pohl MO, Zhou Y, Rodriguez-Frandsen A, Wang G, Stein DA, et al. Meta- and orthogonal integration of influenza "OMICs" data defines a role for UBR4 in virus budding. Cell Host Microbe. (2015) 18:723-35. doi: 10.1016/j.chom.2015.11.002

32. Steinbaugh M, Turner S, Wolen A. stephenturner/annotables: Ensembl 90 (Version v0.1.90). Charlottesville, VA:Zenodo (2017).

33. Szklarczyk D, Gable AL, Lyon D, Junge A, Wyder S, Huerta-Cepas J, et al. STRING v11: protein-protein association networks with increased coverage, supporting functional discovery in genome-wide experimental datasets. Nucleic Acids Res. (2019) 47:D607-13. doi: 10.1093/nar/gky1131

34. Tsugawa H, Cajka T, Kind T, Ma Y, Higgins B, Ikeda K, et al. MS-DIAL: dataindependent MS/MS deconvolution for comprehensive metabolome analysis. Nat Methods. (2015) 12:523-6. doi: 10.1038/nmeth.3393

35. Kind T, Liu KH, Lee DY, DeFelice B, Meissen JK, Fiehn O. LipidBlast in silico tandem mass spectrometry database for lipid identification. Nat Methods. (2013) 10:755-8. doi: 10.1038/nmeth.2551

36. Su X, Abumrad NA. Cellular fatty acid uptake: a pathway under construction. Trends Endocrinol Metab. (2009) 20:72-7. doi: 10.1016/j.tem.2008. 11.001

37. Silverstein RL, Febbraio M. CD36, a scavenger receptor involved in immunity, metabolism, angiogenesis, and behavior. Sci Signal. (2009) 2:re3. doi: $10.1126 /$ scisignal.272re3

38. Eberle D, Hegarty B, Bossard P, Ferre P, Foufelle F. SREBP transcription factors: master regulators of lipid homeostasis. Biochimie. (2004) 86:839-48. doi: 10.1016/j.biochi.2004.09.018

39. Yue L, Mazzone T. Peroxisome proliferator-activated receptor \{gamma\} stimulation of adipocyte ApoE gene transcription mediated by the liver receptor X pathway. J Biol Chem. (2009) 284:10453-61. doi: 10.1074/jbc.M808482200

40. Chawla A, Boisvert WA, Lee CH, Laffitte BA, Barak Y, Joseph SB, et al. A PPAR gamma-LXR-ABCA1 pathway in macrophages is involved in cholesterol efflux and atherogenesis. Mol Cell. (2001) 7:161-71. doi: 10.1016/S1097-2765(01)00164-2
41. Horkko S, Bird DA, Miller E, Itabe H, Leitinger N, Subbanagounder G, et al. Monoclonal autoantibodies specific for oxidized phospholipids or oxidized phospholipid-protein adducts inhibit macrophage uptake of oxidized lowdensity lipoproteins. J Clin Invest. (1999) 103:117-28. doi: 10.1172/JCI4533

42. Schmitz G, Grandl M. Endolysosomal phospholipidosis and cytosolic lipid droplet storage and release in macrophages. Biochim Biophys Acta. (2009) 1791:524-39. doi: 10.1016/j.bbalip.2008.12.007

43. Lee G, Elwood F, McNally J, Weiszmann J, Lindstrom M, Amaral K, et al. T0070907, a selective ligand for peroxisome proliferator-activated receptor gamma, functions as an antagonist of biochemical and cellular activities. J Biol Chem. (2002) 277:19649-57. doi: 10.1074/jbc.M200743200

44. Rodrigue-Way A, Caron V, Bilodeau S, Keil S, Hassan M, Levy E, et al. Scavenger receptor CD36 mediates inhibition of cholesterol synthesis via activation of the PPARgamma/PGC-1alpha pathway and Insig1/2 expression in hepatocytes. FASEB J. (2014) 28:1910-23. doi: 10.1096/fj.13-240168

45. Shimano H, Sato R. SREBP-regulated lipid metabolism: convergent physiology - divergent pathophysiology. Nat Rev Endocrinol. (2017) 13:71030. doi: 10.1038/nrendo.2017.91

46. Ginhoux F. Fate PPAR-titioning: PPAR-gamma 'instructs' alveolar macrophage development. Nat Immunol. (2014) 15:1005-7. doi: $10.1038 /$ ni.3011

47. Baker AD, Malur A, Barna BP, Ghosh S, Kavuru MS, Malur AG, et al. Targeted PPAR \{gamma\} deficiency in alveolar macrophages disrupts surfactant catabolism. J Lipid Res. (2010) 51:1325-31. doi: 10.1194/jlr.M001651

48. Baker AD, Malur A, Barna BP, Kavuru MS, Malur AG, Thomassen MJ. PPARgamma regulates the expression of cholesterol metabolism genes in alveolar macrophages. Biochem Biophys Res Commun. (2010) 393:682-7. doi: 10.1016/j.bbrc.2010.02.056

49. Hauser S, Adelmant G, Sarraf P, Wright HM, Mueller E, Spiegelman BM. Degradation of the peroxisome proliferator-activated receptor gamma is linked to ligand-dependent activation. J Biol Chem. (2000) 275:18527-33. doi: 10.1074/jbc.M001297200

50. Chang CC, Hsieh MS, Liao ST, Chen YH, Cheng CW, Huang PT, et al. Hyaluronan regulates PPARgamma and inflammatory responses in IL1beta-stimulated human chondrosarcoma cells, a model for osteoarthritis. Carbohydr Polym. (2012) 90:1168-75. doi: 10.1016/j.carbpol.2012.06.071

51. Acharya PS, Majumdar S, Jacob M, Hayden J, Mrass P, Weninger W, et al. Fibroblast migration is mediated by CD44-dependent TGF beta activation. $J$ Cell Sci. (2008) 121:1393-402. doi: 10.1242/jcs.021683

52. Bourguignon LYW, Singleton PA, Zhu HB, Zhou B. Hyaluronan promotes signaling interaction between CD44 and the transforming growth factor beta receptor I in metastatic breast tumor cells. J Biol Chem. (2002) 277:39703-12. doi: 10.1074/jbc.M204320200

53. Aziz A, Soucie E, Sarrazin S, Sieweke MH. MafB/c-Maf deficiency enables selfrenewal of differentiated functional macrophages. Science. (2009) 326:867-71. doi: 10.1126/science.1176056

54. Moliva JI, Rajaram MV, Sidiki S, Sasindran SJ, Guirado E, Pan XJ, et al. Molecular composition of the alveolar lining fluid in the aging lung. Age. (2014) 36:9633. doi: 10.1007/s11357-014-9633-4

Conflict of Interest: The authors declare that the research was conducted in the absence of any commercial or financial relationships that could be construed as a potential conflict of interest.

Copyright (C) 2020 Dong, Arif, Guo, Ha, Lee-Sayer, Poon, Dosanjh, Roskelley, Huan and Johnson. This is an open-access article distributed under the terms of the Creative Commons Attribution License (CC BY). The use, distribution or reproduction in other forums is permitted, provided the original author(s) and the copyright owner(s) are credited and that the original publication in this journal is cited, in accordance with accepted academic practice. No use, distribution or reproduction is permitted which does not comply with these terms. 